\title{
Una ocupación con cerámica temprana en la secuencia del distrito de Cáñamo (costa desértica del norte de Chile)
}

Lautaro Núñez A. ${ }^{1}$ y Cora Moragas W. ${ }^{2}$

\section{Introducción}

La presente síntesis corresponde a un proyecto iniciado en la localidad de Cáñamo $(60 \mathrm{~km}$ al sur de Iquique), durante 1964, patrocinado por la Universidad de Chile, sede Antofagasta. En dicha oportunidad colaboraron Luis Briones, Patricio Núñez y el geólogo Juan Varela, a quienes agradecemos. Posteriormente el encargado de este proyecto (L. Núñez) prosiguió las indagaciones al tanto que recibió las dataciones radiocarbónicas que indicaban cambios agrocerámicos tempranos, estimulando nuevos estudios tendientes a formular una secuencia cultural como instrumento previo a la definición del proceso de continuidad y cambio. Posteriormente, durante 1977, los autores han revaluado esta situación, poniendo más atención en la imposición de los cambios agrocerámicos a través de un test cuantitativo y de control radiocarbónico que se incluye en esta síntesis. Desgraciadamente, esta prueba estratigráfica probablemente sea la última que se pueda realizar en uno de los yacimientos excavados más representativos, por cuanto una obra de caminos lo ha perturbado en su integridad (Cáñamo 1).

\section{El ambiente}

El distrito arqueológico de Cáñamo se caracteriza por diversos rasgos geomorfológicos que describimos de este a oeste (Figura 1):

a) Nivel de pampa. Ubicado inmediatamente hacia el oriente de la cordillera de la Costa, en un promedio inicial de $600 \mathrm{~m} . \mathrm{snm}$, es una extensión planiforme, que permite un acceso definido hacia la depresión intermedia o pampa del Tamarugal.

1 Departamento de Arqueología, Facultad de Ciencias Sociales de la Universidad del Norte, Antofagasta, y Museo Arqueológico de San Pedro de Atacama, CHILE.

2 Departamento de Arqueología de la Facultad de Ciencias Sociales, Universidad del Norte, Antofagasta, CHILE. b) Cordillera de la Costa. Corresponde al relieve más destacado del área con una orientación norte-sur y dos alteraciones: una punta orientada hacia el mar (Punta Patache) y una curva hacia el sur, que da lugar a una ensenada. Esta cordillera presenta una cota cuspidal de $759 \mathrm{~m} . \mathrm{snm}$, y en un espacio de $1.5 \mathrm{~km}$ promedio, desciende abruptamente hacia la cota de $50 \mathrm{~m}$, constituyendo un barranco pronunciado. Hacia el lado oeste de la cordillera se aprecia un espacio plano y bajo.

c) Terrazas marinas. En las cercanías de caleta Cáñamo se aprecian dos niveles de aterrazamientos. La terraza 1 corresponde al nivel más alto, cuyos mejores remanentes están apegados al barranco de la cordillera de la Costa en el sector norte del distrito.

La terraza 2 equivale a un nivel inferior, y se observa claramente en el sector norte de caleta Cáñamo, constituyendo un relieve planiforme extenso. Esta terraza está mejor difundida que la anterior. Asciende desde los acantilados costeros (cliffs muertos) con una altura de 70 a $80 \mathrm{~m}$, hasta alcanzar una máxima expresión en unos $100 \mathrm{~m}$ hacia el interior. Se compone especialmente de restos de conchas, como Glicimeris, Pecten con gastropos, sal y clastos poco rodados. En el momento en que se labraba esta terraza baja, los islotes ubicados en las puntas que caracterizaron a la terraza alta, dieron lugar a puntas más alargadas que las anteriores.

d) Paleopenínsula. Todo el sector denominado Punta Patache está constituido por afloramientos de elevaciones moderadas que se prolongan hacia el norte, formando un relieve local como una paleopenínsula. Este relieve se acuña formando un vértice final muy cercano a la actual caleta Cáñamo, constituyendo leves barrancos que descienden al litoral, y un descenso gradual hacia el lado occidental, diluyéndose aquí en una extensa playa fósil. En esta vieja península existen afloramientos rocosos dispersos con 


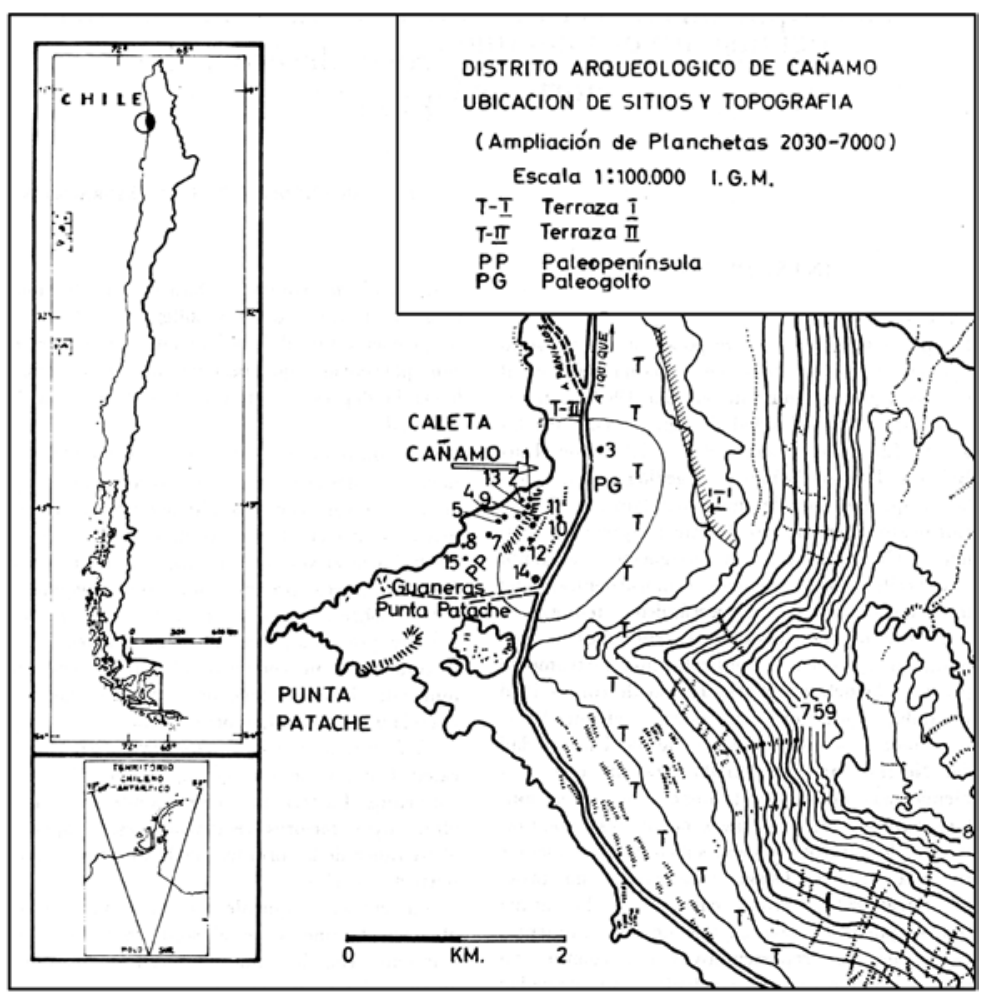

Figura 1. Distrito arqueológico de Cáñamo.

depósitos marinos y ocupación prehistórica, suficientemente concentrada y protegida.

e) Paleogolfo. Ambas terrazas aparecen interrumpidas en el sector de caleta Cáñamo por una explanada que se prolonga desde el mismo nivel del mar (playa Cáñamo) hasta unos 80 a $190 \mathrm{~m}$ al interior, alcanzando el borde de la cordillera de la Costa. Se aprecia claramente que esta depresión o explanada baja fue un antiguo fondo de mar, lo que está atestiguado por las conchas que la constituyen, formándose un extenso golfo que se orienta hacia el sureste, prolongándose tierra adentro.

f) Litoral. Es un litoral rocoso, con escasas playas de arena, especialmente hacia el sector sur de Punta Patache, en donde el barranco cae abruptamente al mar. Al norte de Punta Patache existe un sector de roqueríos bajos de mejor acceso y más útil en términos económicos, que entra en contacto con la llamada caleta Cáñamo. Esta corresponde a una playa de arena, abrigada, siendo el lugar más adecuado para el control marítimo del área.
En este ambiente físico predomina actualmente una cubierta estéril, sin recursos de aguas, con una humedad restringida sólo a las temporadas de invierno, en donde las neblinas rasantes dan lugar a una vegetación de cactus relictuales en las pendientes y cumbres de la cordillera de la Costa. Esta recarga hídrica atmosférica también pudo favorecer el desarrollo de otros recursos vegetales, como junquillos, en cuyas raíces crece una especie de bulbo sólido o cormos (Zephira elegans D. Don.), pertenecientes a las Tecofiláceas.

La prospección no registró vertientes secas generadas por fallas ni por neblinas rasantes, como se ha definido para la costa sur de Iquique (Núñez y Varela 1967-68). Sin embargo, la presencia estable de asentamientos humanos con cierta continuidad durante aproximadamente 3000 años, permite suponer la existencia de un leve recurso local, aunque no necesariamente debe establecerse en este distrito. Existe la posibilidad de que hubiera algún depósito por neblinas en las altas cumbres de la cordillera de la Costa, pero creemos más en la factibilidad de que en el área de Patillos (al norte de caleta Cáñamo) 
existiera un afloramiento hídrico. Esto explicaría la presencia de poblaciones precerámicas y agroalfareras densas en esta localidad, que demuestran una efectiva estabilidad. Estos desplazamientos hasta Patillos $(3 \mathrm{~km})$ pueden considerarse aún menores, por cuanto recolectaban algarrobos en el Tamarugal, distante entre 40 a $50 \mathrm{~km}$, en el nivel de pampa. En consecuencia, estamos en presencia de una población que manipula el paisaje con una orientación muy dinámica, pudiendo abastecerse de agua en afloramientos distantes de Cáñamo.

El déficit de agua local parece que ejerció un límite en el desarrollo de los asentamientos, lo cual se puede comprobar por las estructuras monticulares y restringidas de los desperdicios depositados por grupos de densidad relativamente reducida que persistieron con cierta estabilidad dentro del área. En oposición a esto, se destaca la gran importancia del litoral, que por su alta productividad permite una explotación intensiva en términos de pesca, caza y recolección como actividades predominantes.

Los desperdicios cuantificados, además de señalar la presencia de alimentos marinos, indican la existencia significativa de bulbos de la familia Tecofiláceas y de cactáceas, ambas recolectadas de los cerros del litoral. Al tanto que usufructuaban de intensas cosechas de algarrobo en los veranos tardíos (?) en la Pampa del Tamarugal, se alimentaban de cultígenos trasladados desde hábitats interiores.

Por otra parte, existe una baja utilización de fauna terrestre a juzgar por la ausencia de forraje local, lo cual demuestra que el medio ecológico era explotado principalmente en base a pesca y recolección marítima.

En suma, el ambiente ecológico del distrito de Cáñamo provee de un mínimo recurso de agua, capaz de sustentar débiles ocupaciones estables. Estos grupos subsistían de los recursos marítimos, en especial de la recolección de mariscos y pesca con anzuelos. Los complementos de caza y recolección terrestre fueron muy escasos, igualmente los aportes agrarios, de donde se deduce que no se logró un equilibrio total en la dieta alimenticia.

\section{Sitios arqueológicos del área de Cáñamo}

Cáñamo 1. Es un basural monticular aislado, protegido hacia el sur por un afloramiento rocoso, ubicado en el área central de la llamada península de Cáñamo. Presenta escasa cerámica en superficie. El yacimiento se caracteriza por una ocupación continua iniciada algo antes de los 2010 \pm 136 años $\mathrm{AC}$, de naturaleza precerámica con un depósito con cerámica temprana, fechada a los $860 \pm 90$ años AC (fecha promedio).

Cáñamo 2. Corresponde a un cementerio de regular densidad con una superficie aproximada de $20 \times 5 \mathrm{~m}$. Se trata de un conchal con fardos funerarios alterados. Este sitio, al parecer, fue el cementerio excavado por A. Nielsen con el nombre de "Cáñamo Norte" ("Gentilar revuelto"). Los contextos culturales parecen corresponder a la población más tardía registrada en el área de Cáñamo.

Cáñamo 3. Cementerio ubicado en la bifurcación entre el actual camino costero y el desvío que desciende a playa Cáñamo. El primer autor durante el año 1964 excavó 23 tumbas, en su mayoría no alteradas. Este cementerio muestra una población culturalmente homogénea, con cuerpos extendidos, semiflectados lateralmente, cubiertos con esteras bajo leves acumulamientos de piedras. Existe una datación radiocarbónica de 760ะ60 DC (Núñez 1976).

Cáñamo 4. Recinto habitacional semisubterráneo con piedras superpuestas dispuesto entre desperdicios marítimos. Fue excavado por el primer autor. A juzgar por la presencia de un molde metalúrgico de cerámica y de cabeceras de arpón de hueso, podría ubicarse en una etapa tardía, ya que se han registrado moldes similares en la aldea de Quillagua (Cervellino y Téllez Ms).

Cáñamo 5. Campamento no excavado. Se caracteriza por emplantillados de piedras que constituyen núcleos habitacionales alterados, entremezclados con un depósito de desperdicios marinos, con el mismo patrón de Cáñamo 4. El yacimiento se ubica en la península cerca del mar, y cubre un área aproximada de $10 \times 5 \mathrm{~m}$.

Cáñamo 6. Corresponde a un tiesto cerámico aislado, al sureste de Cáñamo 3.

Cáñamo 7. Basural monticular muy denso, sin alteraciones, similar a Cáñamo 1. Ubicado en la península, cerca del mar, entre afloramientos rocosos, al suroeste de Cáñamo 1.

Cáñamo 8. Basural monticular no alterado de gran densidad, ubicado entre afloramientos rocosos, en 


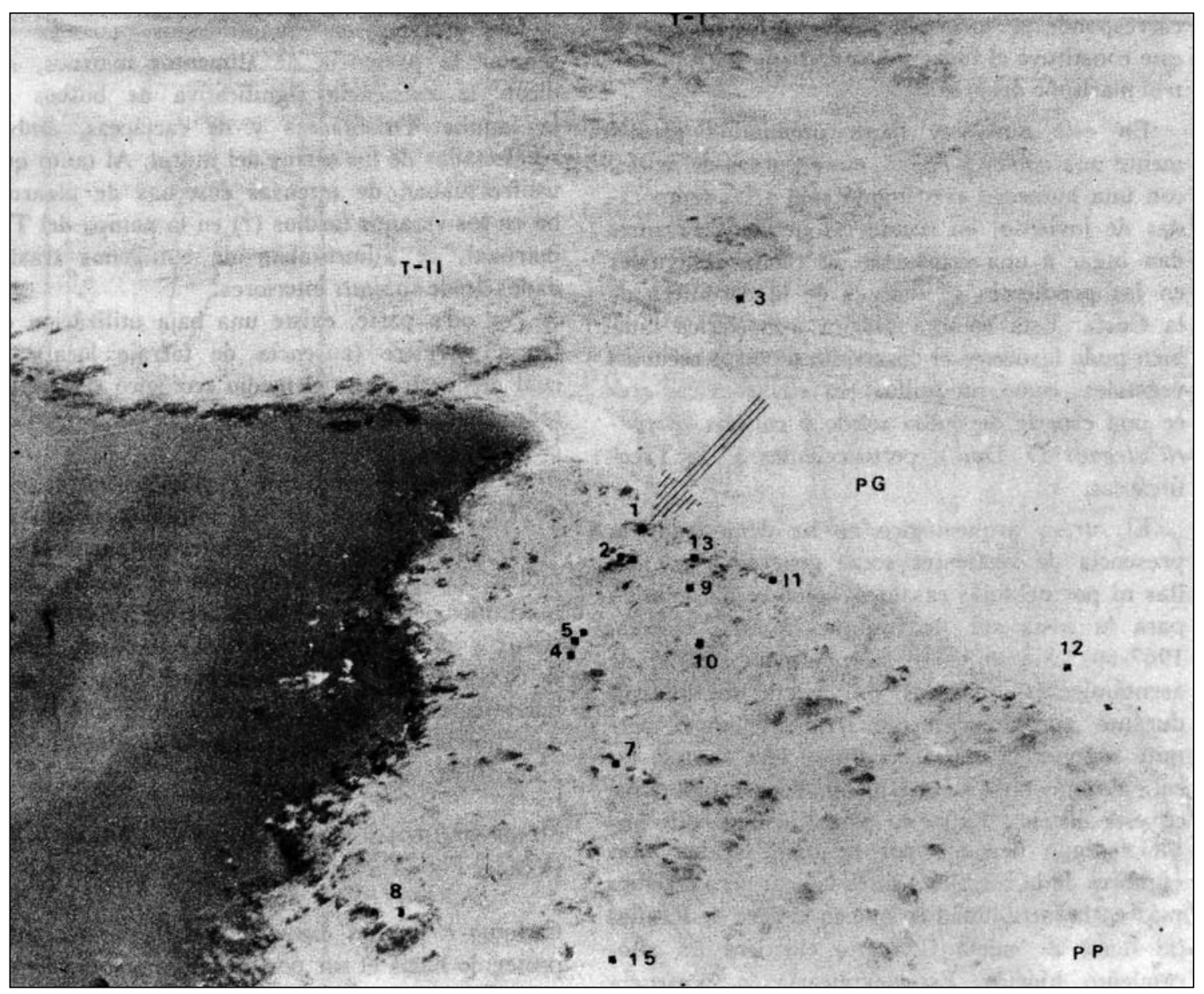

Figura 2. Foto aérea en donde se señalan los sitios arqueológicos numerados. La flecha señala el montículo Cáñamo 1, de donde proviene la ocupación con cerámica temprana fechada en 860 AC (T-I: Terraza superior; T-II: Terraza inferior; PG: Paleogolfo; PP: Paleopenínsula).

el borde occidental de la península cercana al mar. Podría representar una ocupación precerámica similar a Cáñamo 1.

Cáñamo 9. Basural no excavado, con escasas alteraciones, pero de menor potencialidad que las anteriores.

Cáñamo 10. Cementerio alterado ubicado en la península de Cáñamo. Cubre un área de 10 x $5 \mathrm{~m}$. Al parecer es un yacimiento tardío por la presencia de fragmentos de cerámica y tejidos a telar.

Cáñamo 11. Basural poco denso y de poca extensión. No excavado. Se ubica en la península de Cáñamo.
Cáñamo 12. Cementerio relativamente amplio, con un área de 40 x $20 \mathrm{~m}$. Se ubica en el sector occidental del llamado paleogolfo. Se registraron 12 tumbas alteradas, ubicándose cronológicamente en una etapa pretardía. Este yacimiento parece corresponder al sitio excavado por A. Nielsen con el nombre de "Cáñamo Sur".

Cáñamo 13. Basural monticular no alterado ni excavado. Se ubica junto a un afloramiento rocoso, al sur del basural Cáñamo 1. En este sitio hicimos en 1977 tres test estratigráficos de $1 \mathrm{~m}^{2}$ cada uno, cuyo análisis ofreció material no diagnóstico (Tabla 2).

Cáñamo 14. Campamento histórico de comienzos del siglo XX. 
Cáñamo 15. Basural conchífero de poca extensión y escasa profundidad. Se ubica en la paleopenínsula al sur de otro basural de mayor densidad (Cáñamo 8).

\section{Estratigrafía del sitio Cáñamo 1}

Los componentes cerámicos tempranos que caracterizan a la fase Cáñamo Montículo fueron registrados en el basural Cáñamo 1. Este sitio corresponde a un montículo de $36 \mathrm{~m}$ de largo N-S por $40 \mathrm{~m}$ de ancho E-O con una altura relativa cercana a $2 \mathrm{~m}$, equivalente a $460 \mathrm{~m}^{2}$ de desperdicios, protegidos por un afloramiento rocoso de mayor altura. Durante dos temporadas (1964 y 1965) el primer autor escavó tres trincheras con estratos que encerraron un bloque de $6.5 \times 6.5 \mathrm{~m}$, controlados por estratigrafía cultural (Figura 3).

La estratigrafía vista en la excavación anterior, como en el test reciente (1977), manifiesta perfiles con un claro manteo de sur a norte, debido a la pendiente subyacente.

Al observar el perfil E-O de la excavación de 1964 (Figura 4) se destaca una disposición estratigráfica compleja caracterizada por superposiciones de fogones, estratos de desperdicios fértiles y depósitos semiestériles con predominio de arena eólica. El espacio entre ambos cortes de inspección presenta un estrato I caracterizado por una pigmentación amarilla derivada de desperdicios orgánicos marítimos bien conservados con predominio de erizo. Presenta componentes cerámicos mayoritarios, y una datación radiocarbónica promedio de 860 años AC.

Bajo el estrato I se disponen fogones compactos que establecen una clara separación con el estrato II, el que se caracteriza por desperdicios mezclados con arena eólica predominante, restándole fertilidad al depósito que contiene escasos fragmentos cerámicos. En la base de este estrato se disponen lentes de plumas, conchas y fogones.

El estrato III corresponde a depósitos de desperdicios sobrepuestos a la base estéril del montículo. En otros sectores del depósito aparece el estrato IV o inferior, con desperdicios mezclados con guano de ave, constituyendo la base de la ocupación. El estrato III fue fechado en 2010 años AC, a través de carbones de un lente que sitúa el comienzo de su depositación (Figura 5). La Tabla 1 muestra registro de cerámicas en el estrato III, pero ésta se encontró en el techo terminal del estrato, intercalándose alguna en el comienzo del estrato II. Los dos fragmentos de cerámica que aparecen en el estrato IV los consideramos dudosos o intrusivos por acción accidental.

Un perfil-testigo (perfil E-O, sección sur) de esta misma excavación (ver Figura 5) muestra los cuatro estratos principales señalando los lugares del muestreo radiocarbónico.

Durante el verano 1977, una vez ya alterado el yacimiento, los autores realizaron un test de $2 \times 1.30 \mathrm{~m}$, en un sector no perturbado por las obras de vialidad. El nuevo resultado radiocarbónico se considera coherente y es comentado más adelante, y los controles cuantitativos complementaron el trabajo de campo de los años anteriores.

\section{Análisis del material cultural del sitio Cáñamo 1}

Al observar la Tabla 1, se desprenden varias consideraciones sobre los componentes culturales del yacimiento Cáñamo 1.

\section{Material lítico}

A. Litos no modificados. La presencia de rodados naturales procedentes de las playas son comunes en todos los estratos, aumentando en el III y I, respectivamente. Fueron usados como percutores, manos, etc.

Los desechos de percusión se presentan desde los estratos inferiores, aumentando su frecuencia en los estratos I y II de mayor fertilidad. Se presentan además lascas no modificadas con marcas en sus bordes como consecuencia del uso de corte y raído, confeccionadas principalmente en cuarzo con sus variedades blanco y rosado. Predominan las lascas cortantes naturales sobre los bordes presionados de artefactos modificados. Estas lascas usadas serían cuchillos ocasionales, relacionadas a la alimentación marítima faenada en el lugar.

Pequeñas placas como lajas aparecen en el estrato II y en mayor cantidad en el estrato I. Pudieron utilizarse como plataformas de percusión o como especies de afiladores y aun para preparar pinturas, de acuerdo a los restos de pigmento rojo. Su ausencia en la etapa temprana parece ser accidental. 
LAUTARO NUÑEZ A., CORA MORAGAS W.

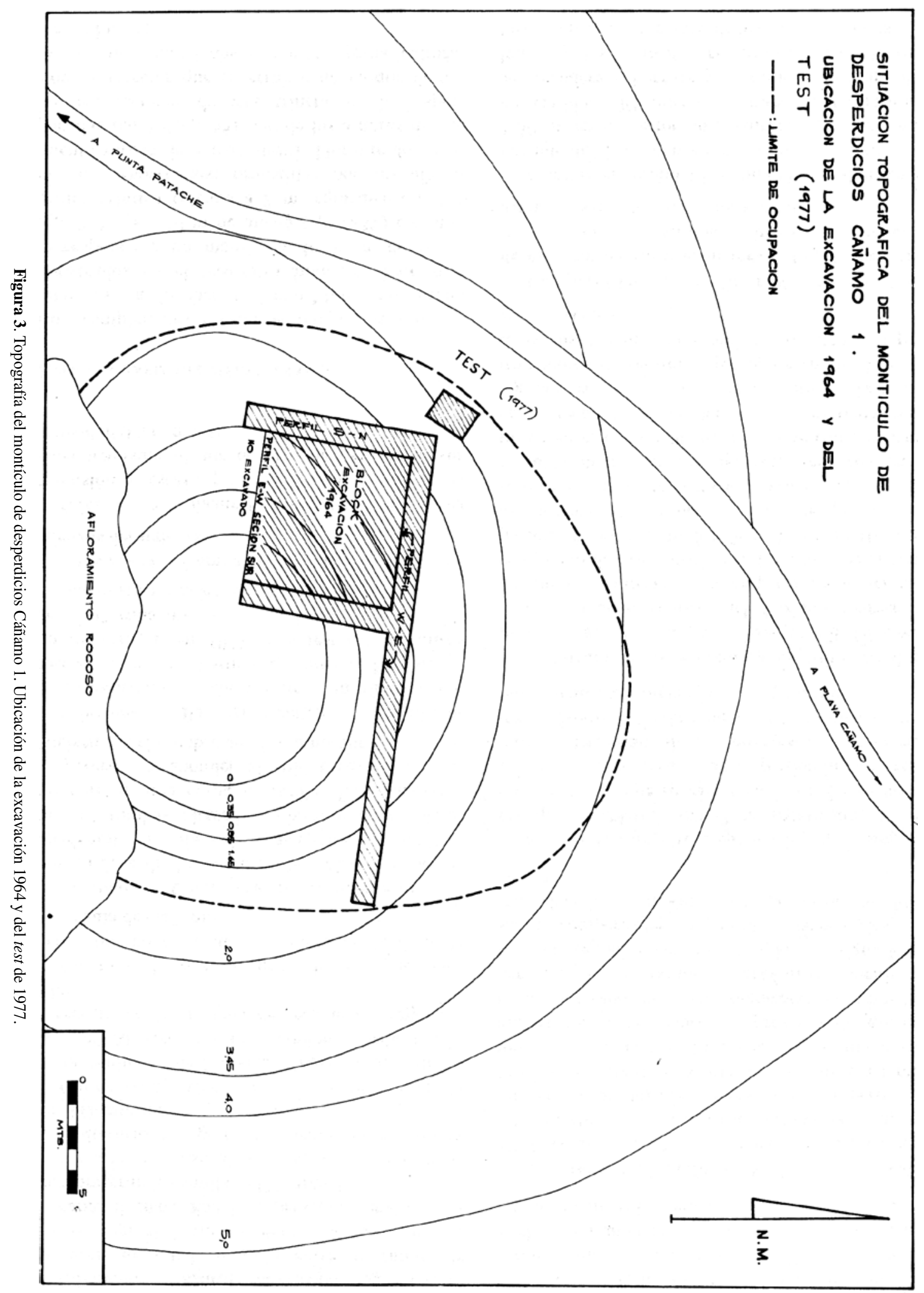




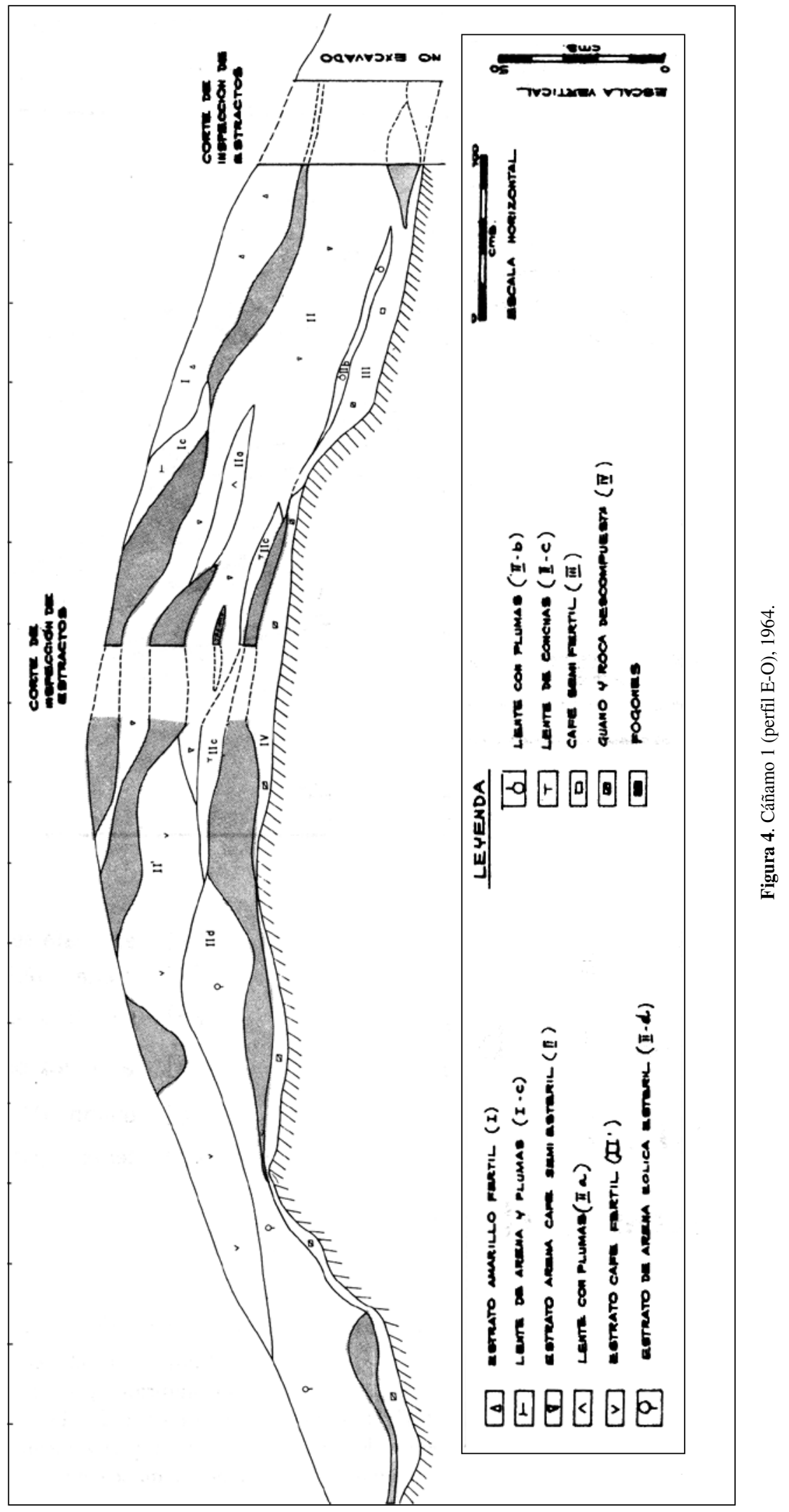




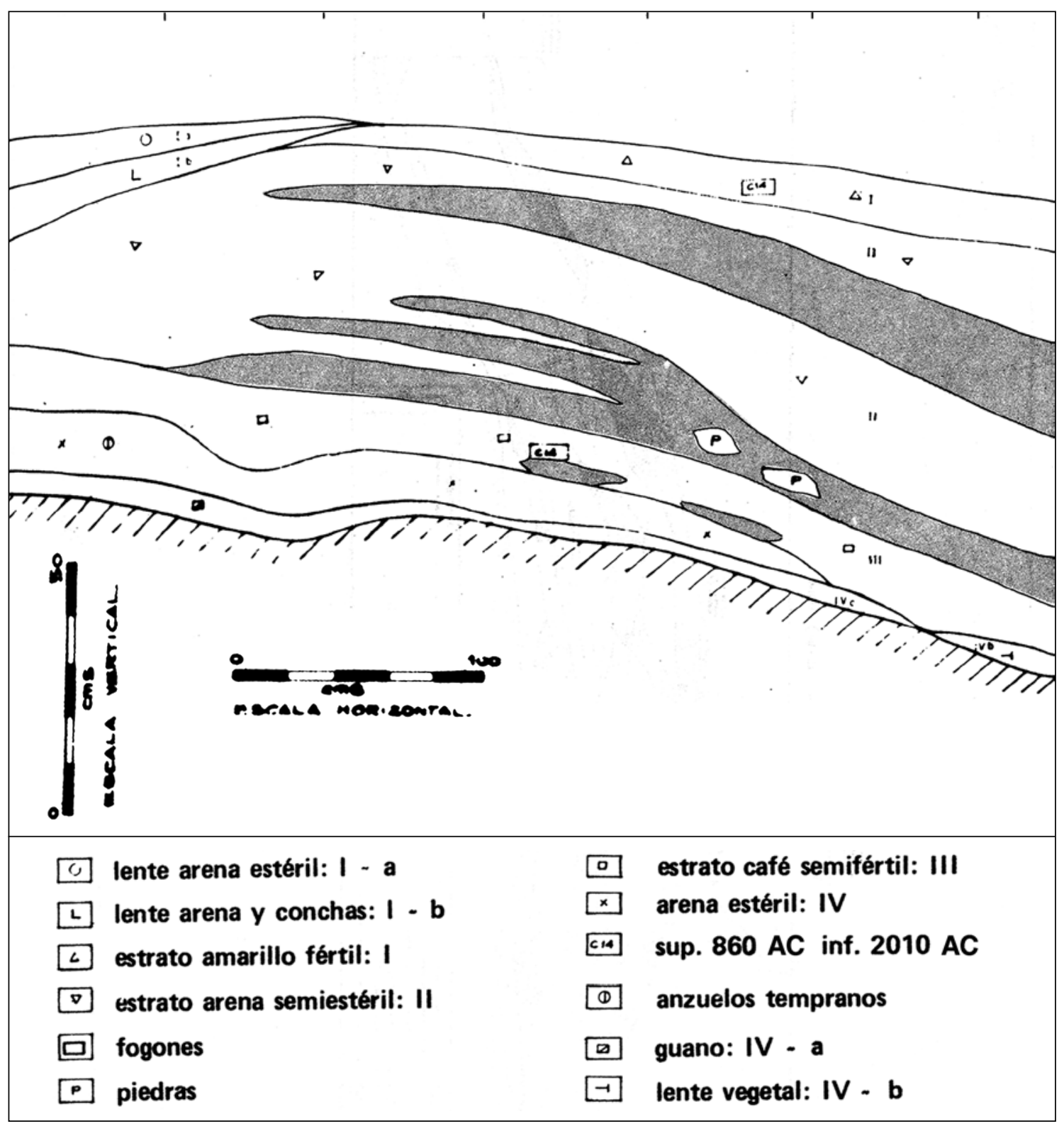

Figura 5. Perfil E-O (testigo), Cáñamo 1. Se señala el muestreo radiocarbónico y la sucesión estratigráfica.

Los nódulos aparecen en el estrato III en pequeña cantidad y aumentan hacia la superficie. Su ausencia en los estratos inferiores parece indicar que los grupos tempranos no habrían elaborado herramientas de núcleos.

Finalmente, destacan piedras naturales que presentan amarras para ser usadas como pesas. Aparecen en el estrato II y aumentan hacia el I. Se trataría de un rasgo tardío que complementa la función de las pesas-cigarro.
B. Litos modificados. Los choppers corresponden a rodados percutidos registrados en todos los estratos, aunque su número aumenta en el estrato III. También las matrices están presentes en todos los estratos, pero esta vez su concentración ocurre en el estrato I. Las formas predominantes en este grupo constituyen cuchillos en elaboración, lo cual confirma nuestra sugerencia de que estas herramientas eran las más populares dentro del yacimiento, relacionadas con el faenamiento de alimentos in situ. 


\begin{tabular}{|c|c|c|c|c|c|}
\hline Rastros culturales diagnósticos & Sup. & $\begin{array}{c}\text { E-1 } \\
\text { I, la. Ib, Ic }\end{array}$ & $\begin{array}{c}\text { E-II } \\
\text { II, II', IIa, IIb, IIc, IId }\end{array}$ & $\begin{array}{c}\text { E-III } \\
\text { III }\end{array}$ & $\begin{array}{c}\text { E-IV } \\
\text { IV, IVa, IVb }\end{array}$ \\
\hline \multicolumn{6}{|l|}{ 1. Material lítico } \\
\hline \multicolumn{6}{|l|}{ A. Litos no modificados } \\
\hline 1.1. Rodados & 1 & 52 & 7 & 17 & 35 \\
\hline 1.2 Desechos de percusión y lascas no modificadas & 6 & 248 & 115 & 440 & 152 \\
\hline 1.3. Lajas & 1 & 14 & 1 & & \\
\hline 1.4. Pesas naturales & & 5 & 1 & & \\
\hline 1.5. Lascas con uso & & 9 & 2 & & 5 \\
\hline 1.6. Nódulos & & 58 & 42 & 51 & \\
\hline \multicolumn{6}{|l|}{ B. Litos modificados } \\
\hline 1.7. Rodados (choppers) & & 31 & 9 & 89 & 9 \\
\hline 1.8. Lascas modificadas & 4 & 187 & 106 & 273 & 155 \\
\hline 1.9. Matrices & 1 & 132 & 36 & 22 & 40 \\
\hline 1.10. Puntas triangulares base recta & & 2 & & 2 & \\
\hline 1.11. Puntas lanceoladas & & 1 & 1 & 1 & 1 \\
\hline 1.12. Punta base escotada & & 3 & 1 & 2 & 1 \\
\hline 1.13. Puntas pedunculadas & & 2 & 2 & 1 & 1 \\
\hline 1.14. Cuchillo triangular base recta & & 7 & 4 & 11 & \\
\hline 1.15. Cuchillos lanceolados y medio alunados & 1 & 6 & 7 & 3 & 4 \\
\hline 1.16. Cuchillo base escotada & & 3 & 3 & 5 & 1 \\
\hline 1.17. Raederas & & 4 & 1 & & \\
\hline 1.18. Raspadores & 1 & 1 & & & \\
\hline 1.19. Perforadores & 2 & 5 & 1 & 3 & \\
\hline 1.20. Pesas-cigarros & 1 & 3 & & & \\
\hline \multicolumn{6}{|l|}{ 2. Huesos modificados } \\
\hline 2.21. Ganchos de potera & & & & 2 & \\
\hline 2.22. Espátulas & & & 6 & 4 & \\
\hline 2.23. Chope o desconchador & & 35 & 7 & 27 & 3 \\
\hline 2.24. Punzones & & & 8 & 2 & \\
\hline 2.25. Barbas de arpón & & 2 & & 2 & 2 \\
\hline 2.26. Anzuelos de barbas de ballena & & & & & 14 \\
\hline \multicolumn{6}{|l|}{ 3. Madera modificada } \\
\hline 3.27. Madera de extremo aguzado & & 2 & & 4 & \\
\hline 3.28. Fragmento extendedor de remo o arpón & & 3 & & & \\
\hline 3.29. Yesquero & & & & 4 & 5 \\
\hline 3.30. Eje de potera & & & & 1 & \\
\hline 3.31. Fragmentos cilíndricos & & & & 5 & 6 \\
\hline 3.32. Mangos de cuchillos & & & & 2 & \\
\hline 3.33. Objeto como tapón & & & & 1 & 2 \\
\hline 3.34. Espatuliformes & & & & 1 & \\
\hline \multicolumn{6}{|l|}{ 4. Conchas modificadas } \\
\hline 4.35. Pesas & & 3 & 5 & & 1 \\
\hline 4.36. Cuentas de collar & & 3 & & & 1 \\
\hline 4.37. Depósito de pintura & & 7 & 1 & 2 & 2 \\
\hline 4.38. Choromytilus con uso en bisel & & 1 & & & \\
\hline \multicolumn{6}{|l|}{ 5. Cestería } \\
\hline 5.39. Cestería coiled & 1 & 3 & & & 1 \\
\hline \multicolumn{6}{|l|}{ 6. Tejidos } \\
\hline 6.40. Tejido de lana & 2 & 8 & 2 & 2 & 1 \\
\hline 6.41. Tejido vegetal & & 2 & 3 & 2 & 1 \\
\hline 6.42. Tejidos mixtos & & 6 & 1 & & \\
\hline
\end{tabular}

Tabla 1. Frecuencias de rasgos culturales en Cáñamo 1. Excavaciones realizadas en 1964 y 1977 (continúa en la siguiente página). 


\begin{tabular}{|c|c|c|c|c|c|}
\hline Rastros culturales diagnósticos & Sup. & $\begin{array}{c}\text { E-1 } \\
\text { I, la. Ib, Ic }\end{array}$ & $\begin{array}{c}\text { E-II } \\
\text { II, II', IIa, IIb, IIc, IId }\end{array}$ & $\begin{array}{c}\text { E-III } \\
\text { III }\end{array}$ & $\begin{array}{c}\text { E-IV } \\
\text { IV, IVa, IVb }\end{array}$ \\
\hline \multicolumn{6}{|l|}{ 7. Cordelería } \\
\hline 7.43. Cordelería de lana & & 444 & 396 & 156 & 80 \\
\hline 7.44. Cordelería de fibra vegetal & & 412 & 204 & 133 & 63 \\
\hline 7.45. Cordelería de algodón & & 23 & 25 & 1 & \\
\hline 7.46. Pelo humano & & 16 & 28 & 9 & 1 \\
\hline \multicolumn{6}{|l|}{ 8. Vestimentas } \\
\hline 8.47. Cobertura de plumas & & 1 & & & \\
\hline 8.48. Coberturas de fibra vegetal & & & 1 & 1 & \\
\hline 8.49. Cobertura de vellones de lana & & & & 1 & \\
\hline \multicolumn{6}{|l|}{ 9. Cerámica } \\
\hline 9.50 Cáñamo café alisado & 7 & 514 & 23 & 2 & $1(?)$ \\
\hline 9.51. Cáñamo café estriado leve & 2 & 20 & 1 & & \\
\hline 9.52. Cáñamo paleteado y estriado & 1 & 4 & & & \\
\hline 9.53. Cáñamo café pulido & 5 & 9 & 1 & & \\
\hline 9.54. Cáñamo baño rojo & & 16 & & & \\
\hline 9.55. Cáñamo negro semipulido & & 21 & 5 & & \\
\hline 9.56. Misceláneos & 6 & 81 & 6 & 2 & $1(?)$ \\
\hline \multicolumn{6}{|l|}{ 10. Vegetales modificados } \\
\hline 10.57. Espinas de quisco & & 54 & 30 & 10 & 3 \\
\hline 10.58. Anzuelos de quisco & & 15 & 5 & 6 & 4 \\
\hline \multicolumn{6}{|l|}{ 11. Alimentos vegetales } \\
\hline 11.59. Maíz (completos y fragmentos) & & 76 & 10 & & \\
\hline 11.60. Algodón (semillas y vellones) & & 85 & 8 & & \\
\hline 11.61. Algarrobo (semillas y frutos de vainas) & & 3.240 & 656 & 28 & 11 \\
\hline 11.62. "Argentinas" (bulbos) & & 250 & 38 & & \\
\hline 11.63. Calabaza & & 12 & & & \\
\hline \multicolumn{6}{|l|}{ 12. Misceláneos } \\
\hline 12.64. Protúberos y fragmentos bolsas de agua & & 4 & 2 & & \\
\hline 12.65. Mineral de cobre & 1 & 2 & & & \\
\hline 12.66. Placa cobre nativo & 1 & & & & \\
\hline 12.67. Garra ave terrestre & & 1 & & & \\
\hline 12.68. Fibras de nerviación paralela & & 72 & 52 & 10 & \\
\hline 12.69. Coprolitos humanos & & 27 & & & \\
\hline 12.70. Coprolitos posible camélidos & & 4 & & & \\
\hline 12.71. Vellón lana camélido & & 3 & 2 & & 1 \\
\hline
\end{tabular}

Tabla 1. Frecuencias de rasgos culturales en Cáñamo 1. Excavaciones realizadas en 1964 y 1977.

Dentro de los cuchillos se observa una baja frecuencia. Aparecen en el estrato IV en cantidad mínima. Se desarrollan mejor en las etapas medias, persistiendo hasta el estrato I (Figura 6, nos $4,10,11,14$ ).

Las puntas de proyectil (Figura 6, $\mathrm{n}^{\mathrm{os}} 1,2,3,5,6$, $7,8,9,12,13$ ) son relativamente escasas en el sitio y se destacan las formas triangulares de base recta que aparecen desde el estrato III hacia la superficie, estando ausentes en los depósitos más tempranos. Las puntas lanceoladas están presentes en todos los estratos, pero con baja representación. Hay también escasas puntas pedunculadas, una temprana con pedúnculo enunciado en el estrato IV y otras con pedúnculo bien definido en los niveles cerámicos. Llama la atención la baja frecuencia de puntas de proyectil en oposición a otros sitios costeros, deduciéndose de esta manera que hay un déficit de prácticas de caza. Esta inferencia se apoya en la débil presencia de raspadores que normalmente se asocian al faenamiento de animales. Por tal motivo, se podría sugerir que la orientación pescadora y recolectora era predominante en el grupo.

Los perforadores están presentes desde el estrato III hasta la superficie. Predominan los elaborados sobre lasca, con sección triangular, pero en general su popularidad es muy baja. 
Las pesas-cigarro también son escasas y no están presentes en los estratos inferiores y medios. Parece seguro que la pesca con pesa y anzuelo se intensifica en la etapa terminal del yacimiento.

\section{Huesos modificados}

El estrato más temprano del sitio es bastante pobre en industria ósea. Se destaca, sin embargo, un conjunto de 14 anzuelos de barbas de ballena elaborados con el patrón formal del anzuelo de concha; se registraron dentro de un tejido tipo red, depositados a su vez en un canasto, entre los desperdicios (Figura 7, n ${ }^{\circ}$ 9).

Llama la atención que tanto los punzones como desconchadores, espátulas y ganchos de potera (tridentes invertidos) aparezcan en los estratos intermedios con sólo algunos ejemplares derivados del estrato IV. La ausencia de ganchos de poteras en los estratos superiores demostraría la disminución de técnicas de captura por "garabateo", confirmando de este modo la ampliación tardía de la pesca con anzuelo, aunque sabemos que ambas técnicas responden a funciones diferentes.

Los chopes o desconchadores de mariscos (Figura 7, $\left.n^{\circ} 8\right)$ están presentes en todos los estratos, y son notablemente abundantes en los estratos cerámicos, apoyando un énfasis tardío en la recolección de mariscos. Estos artefactos provienen de huesos extraídos de lobos de mar, los cuales no eran cazados comúnmente. Por lo tanto, su captura era apetecida en términos de alimentación y en obtención de materia prima para elaborar medios de trabajo.

Finalmente, las barbas de arpón están presentes en todos los estratos, salvo el II, lo cual parece ser accidental; su baja frecuencia confirma lo señalado anteriormente.

\section{Madera modificada}

Se aprecia que la mayor cantidad de madera trabajada se concentra en los estratos IV al III, pero es probable que ésta se haya empleado a través de todo el yacimiento. Esta materia prima se trasladaba desde la Pampa del Tamarugal y se utilizaba para elaborar yesqueros (artefactos para hacer fuego por fricción), los que están presentes desde los comienzos de la ocupación hasta el estrato III. Su ausencia en las etapas más tardías parece ser accidental. Otro uso particular se observa en la elaboración de mangos de cuchillos, presentes en el estrato III y ausentes en

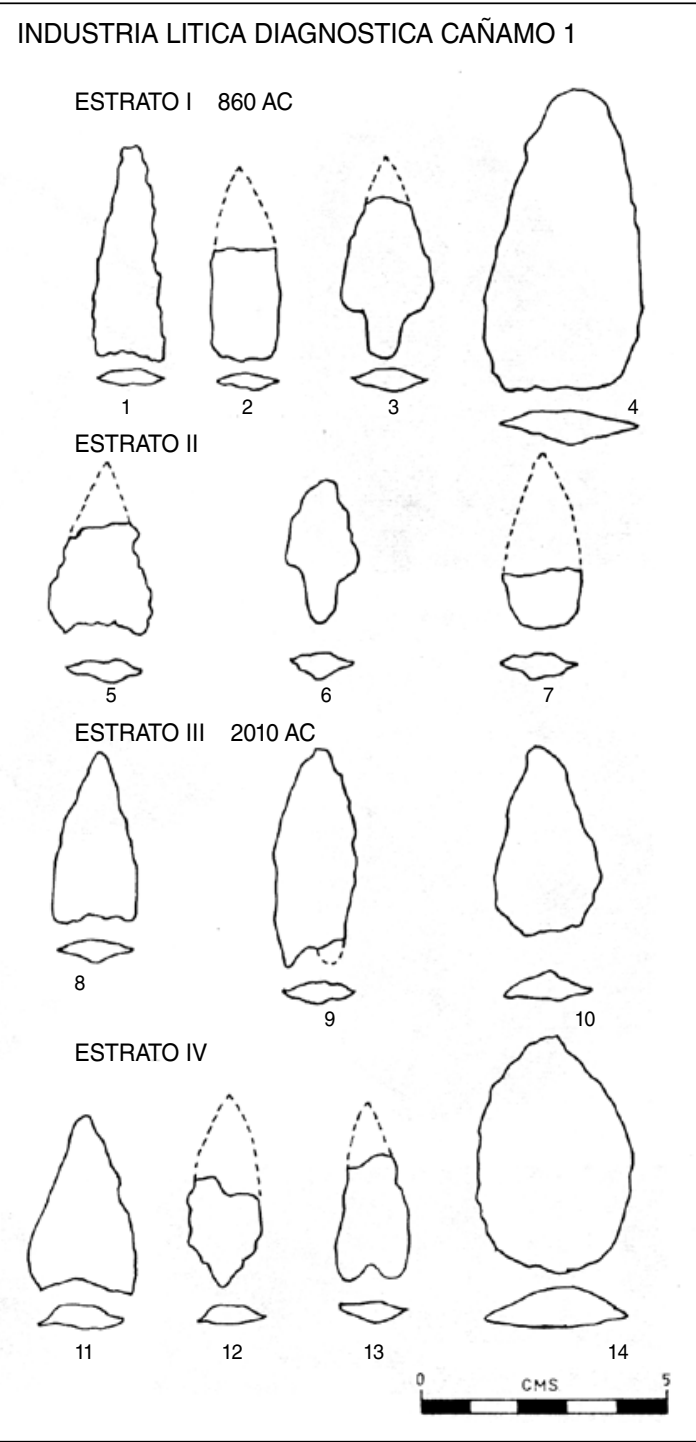

Figura 6. Cuchillos y puntas de proyectil de Cáñamo 1.

ambos extremos. Sin embargo, la presencia de hojas líticas cortantes permite suponer que estos mangos fueron conocidos a través de todo el depósito.

\section{Conchas modificadas}

Se registraron conchas de "señorita" (Patella sp.), locos (Concholepas sp.) y choro azul (Choromytilus chorus) utilizados como recipientes para pintura, especialmente roja, a través de todos los estratos. En la preparación de estos pigmentos se utilizaban manos y morteros, los cuales han aparecido con el mismo pigmento. 
LAUTARO NUÑEZ A., CORA MORAGAS W.

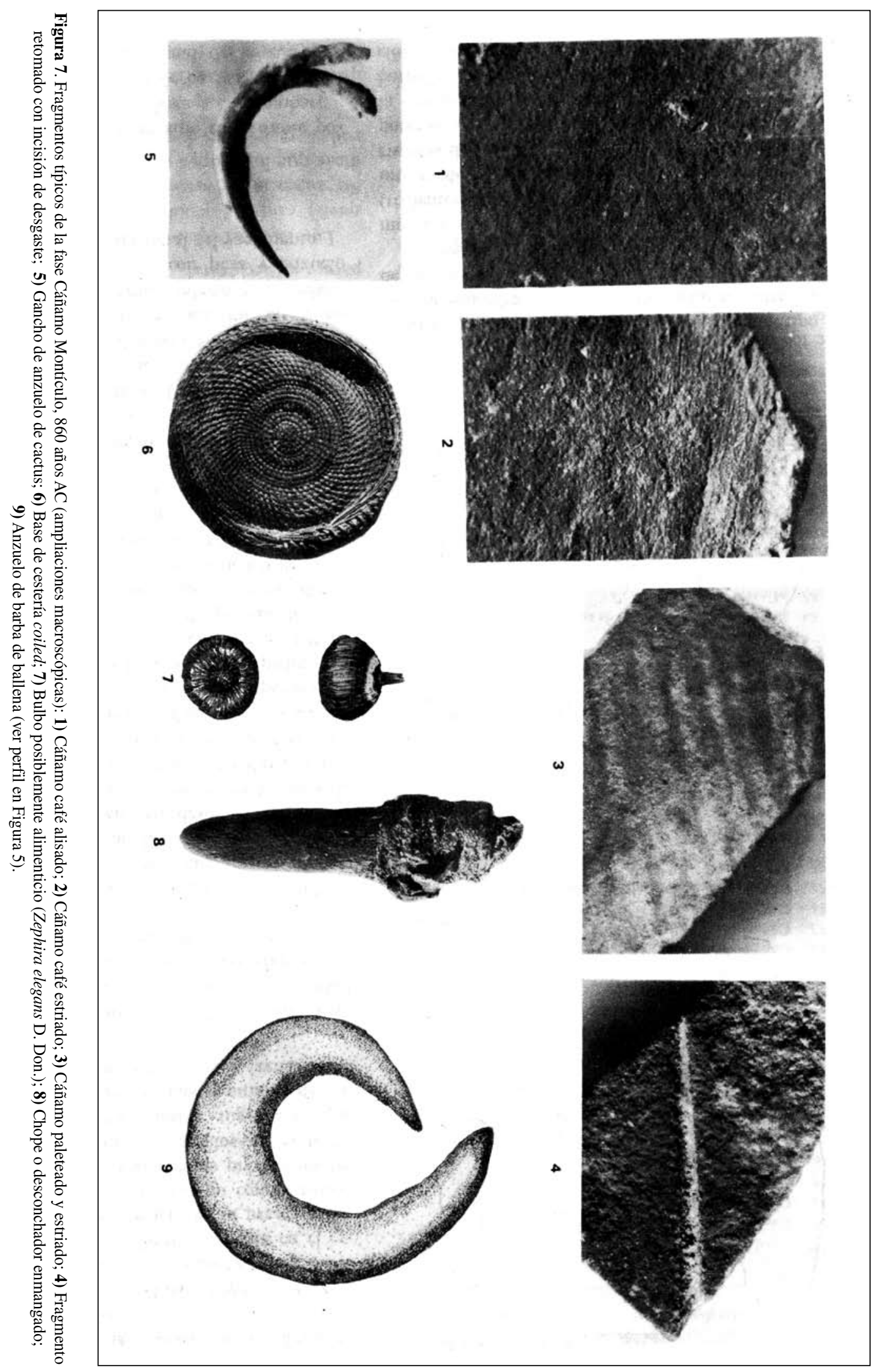


Además se registran conchas de Choromytilus con bordes estriados por acción cortante. Se agregan algunas conchas con amarras (Fisurella o lapa) que han servido como pesas, a través de todo el yacimiento. Frecuencia similar presentan las cuentas de collares.

\section{Cestería}

La industria de cestería (técnica coiled) es poco frecuente, pero está presente desde el estrato IV y posteriormente en el estrato I, dejando un vacío intermedio que parece ser accidental. Su escasa frecuencia se explicaría por la escasez de materia prima local (Figura 7, n⿳0 6).

\section{Tejidos}

Los tejidos de lana de camélidos están presentes en los estratos IV y III, pero en baja frecuencia, a través de técnicas de anudado o malla. Posteriormente, en el estrato II hacia la superficie, se agrega el tejido a telar, asociado a la incorporación de nuevos rasgos agrocerámicos.

Los tejidos de fibra vegetal están presentes en todos los estratos, conservándose tradicionalmente la técnica del anudado. Aparecen además tejidos mixtos con fibra vegetal y lana, en especial en la etapa tardía del yacimiento.

En general, llama la atención la escasez de piezas textiles, tanto anudadas, entrelazadas o a telar, debido tal vez a la escasez de materia prima local, factor que pudo estimular soluciones de reemplazo a base de vestimentas preparadas con plumas de aves, fibras vegetales y vellones de lana de camélido.

\section{Cordelería}

En general, sea cual fuere la materia prima se presenta torcida en S, mayoritariamente a base de dos cabos. La cordelería gruesa (entre 3 a $6 \mathrm{~mm}$ ) pudo ser utilizada como asas, en amarras de vestimentas, portaequipos, etc., es decir, destinadas a levantar pesos considerables. Los fragmentos de regular espesor $(1.5$ y $3 \mathrm{~mm})$ y los finos $(0.5$ y $1.5 \mathrm{~mm}) \mathrm{se}$ relacionan principalmente con las prácticas de pesca con anzuelo. Llama la atención la presencia de nudos de una tecnología muy simple (lazada simple).

Hay cordeles gruesos de lana con mayor frecuencia en los estratos cerámicos que en los más tempranos.
Algo similar ocurre con los cordeles finos, ubicados en todo el depósito con cierta regularidad y cierta tendencia a aumentar en las etapas tardías. Estas evidencias implican un conocimiento persistente de lanas, seguramente de guanaco, procedentes de la cordillera de la Costa o tal vez de vellones de lana de llamas trasladados desde hábitats interiores. $\mathrm{La}$ cordelería de fibra vegetal se comporta de manera muy similar a la anterior, estableciéndose un uso homogéneo que se intensifica en los momentos cerámicos. Las cuerdas de algodón, al contrario de las anteriores, se las utilizó mayoritariamente para la confección de lienzas finas. Los cordeles de espesor regular están presentes con mayor énfasis en los estratos cerámicos, aunque su frecuencia es poco significativa. En general, se destaca un claro predominio de cordeles finos en donde los elaborados en algodón eran más efectivos en relación a las técnicas pesqueras. Este hecho apoya el traslado de estas fibras desde zonas húmedas cercanas. Se complementan estos cordeles con algunos especímenes de pelo humano con espesores regulares y finos en ambas divisiones del depósito, los cuales eran utilizados para lograr amarras de mayor consistencia.

\section{Vestimentas}

Frente al déficit de vestimentas elaboradas con libras de lana a base de tecnologías complejas, se aprecia el uso de algunas vestimentas simples como las coberturas púbicas de fibra vegetal, presentes en los estratos III y II, respectivamente, aunque presumimos que su uso se generalizó en todo el sitio. También aparece un fragmento de cobertura de aves marinas, unida con cordeles de pelo humano (E-I) y otra similar preparada con vellones de lana entrelazada con cuerdas de unión (E-III). Estas coberturas caracterizan un modo particular de vestimentas al parecer persistentes en todos los estratos.

\section{Cerámica}

En la excavación de 1964 se controlaron 615 fragmentos, los cuales se integraron a los registrados en el test del año 1977, en donde se contabilizaron 113 fragmentos (728 en total). A juzgar por este hecho, podemos asegurar que la presencia de cerámica en los estratos tardíos es altamente significativa. Hemos separado siete grupos cerámicos incluyendo una muestra de fragmentos misceláneos y erosionados no diagnósticos. El grupo Cáñamo café alisado con variaciones de homogéneo a más imperfecto, es el más popular de la serie (Figura $7, \mathrm{n}^{\circ} 1$; Figura 8 , 
$\left.\mathrm{n}^{\mathrm{os}} 2,3,4,5\right)$. El grupo Cáñamo café estriado leve, muestra una escasa representación (Figura $7, \mathrm{n}^{\circ} 2$; Figura $\left.8, \mathrm{n}^{\mathrm{os}} 1,6,7\right)$. El grupo Cáñamo paleteado estriado ofrece un paleteado típico ausente en los anteriores, aunque también se complementa con ciertas evidencias de estriamiento; su presencia es menor que los casos anteriores (Figura $7, \mathrm{n}^{\circ} 3$ ). El grupo Cáñamo café pulido señala la aplicación de piedras de pulir en su superficie, y al igual que el grupo anterior, es de baja representación con una situación estratigráfica más bien tardía. El grupo Cáñamo baño rojo ofrece una superficie brillosa, impregnada en un baño rojo, también dispuesto tardíamente. El grupo Cáñamo negro semipulido se inserta en los registros tardíos y sólo algunos fragmentos provienen del estrato II. Finalmente, el grupo misceláneos y erosionados incluye a fragmentos aislados como algunos grises, otros de baja cocción y un buen número de erosionados amorfos (Figura $8, n^{\text {os }} 8,9$ ).

Como se puede apreciar en la Tabla 1, la mayoría de los fragmentos del sitio Cáñamo 1 proviene del estrato I. Sin embargo, en el estrato II hemos detectado algunos fragmentos significativos, especialmente de los grupos Cáñamo café alisado y negro semipulido, por lo que suponemos que durante el estrato II se inicia el contacto cerámico. De esta manera, el estrato II correspondería a una etapa transicional entre los niveles precerámicos y cerámicos, sincrónicos al momento en que habrían arribado los primeros tiestos con superficies alisadas. Esta presencia se ha comprobado a través de dos casos en el techo del estrato III.

En general, podemos indicar que la familia cerámica de Cáñamo 1 (Fase Montículo) se compone de tiestos de cocina con superficies alteradas por quemazones y cambios en las pastas exteriores, a consecuencia de su intercalación con fogones de alta temperatura. Estos tiestos han conservado, además de líquidos, algunas masas de alimentos, a juzgar por las manchas amarillentas orgánicas en el interior de algunos fragmentos. Se trata de una cerámica preparada con alto fundente vinculada con la preparación de alimentos, aparentemente sin uso ceremonial. Siendo una cerámica doméstica, llama la atención la ausencia de asas que parecen determinar un rasgo cultural típicamente temprano. Los grupos de esta fase reutilizaron constantemente los fragmentos desechados, algunos de los cuales aparecen con incisiones profundas, resultantes de trabajos de desgaste y pulimento en relación a la manufactura de conchas, huesos, etc. (Figura 7, $\left.n^{\circ} 4\right)$.

Hemos revisado fuentes bibliográficas y algunas colecciones cerámicas tempranas para establecer algún marco comparativo adecuado. Los tiestos domésticos del complejo Alto Ramírez (Azapa 70) se han fechado hacia 490 años AC (Rivera 1976). En general, resulta interesante mencionar sus asociaciones a maíz, quínoa, porotos, ají, tejidos policromos, trabajos en metal, trasladados desde la cuenca del Titicaca (Pucara). A pesar de que existe una diferencia de 370 años, existen algunas similudes importantes entre Cáñamo y Alto Ramírez:

a) Los desgrasantes de la cerámica de Azapa 70 son predominantemente de arena fina, con algunos casos de corpúsculos mayores aislados.

b) La cocción varía entre oxidante a reductora, y las superficies son siempre monócromas.

c) Generalmente, las superficies presentan manchas de ceniza por efecto de cocina.

d) Al igual que en Cáñamo, muchos fragmentos tienen en su interior restos orgánicos de pigmentación amarilla, a consecuencia de su utilización como envases de alimentos.

e) En algunos casos las superficies presentan leves estriamientos, sobre todo en las internas.

f) Hay alta frecuencia de fragmentos con un tratamiento de alisado homogéneo en sus superficies.

g) En otros casos hay tratamiento superficial de pulimento con espátula muy similar al realizado con piedra en Cáñamo. Como este grupo en Cáñamo es considerado más tardío por su ubicación en superficie, podría corresponder a algún momento sincrónico con la fecha de Azapa 70.

h) Respecto de las formas, se comprueba que tanto en Azapa 70 como en Cáñamo predominan los bordes evertidos, cuerpos globulares y ausencia de asas.

Estas relaciones adquieren mayor relevancia si tomamos en cuenta que los túmulos de Azapa son yacimientos esencialmente funerarios, en contraposición con estos depósitos de desperdicios. En 
UNA OCUPACION CON CERAMICA TEMPRANA EN LA SECUENCIA DEL DISTRITO DE CAÑAMO..

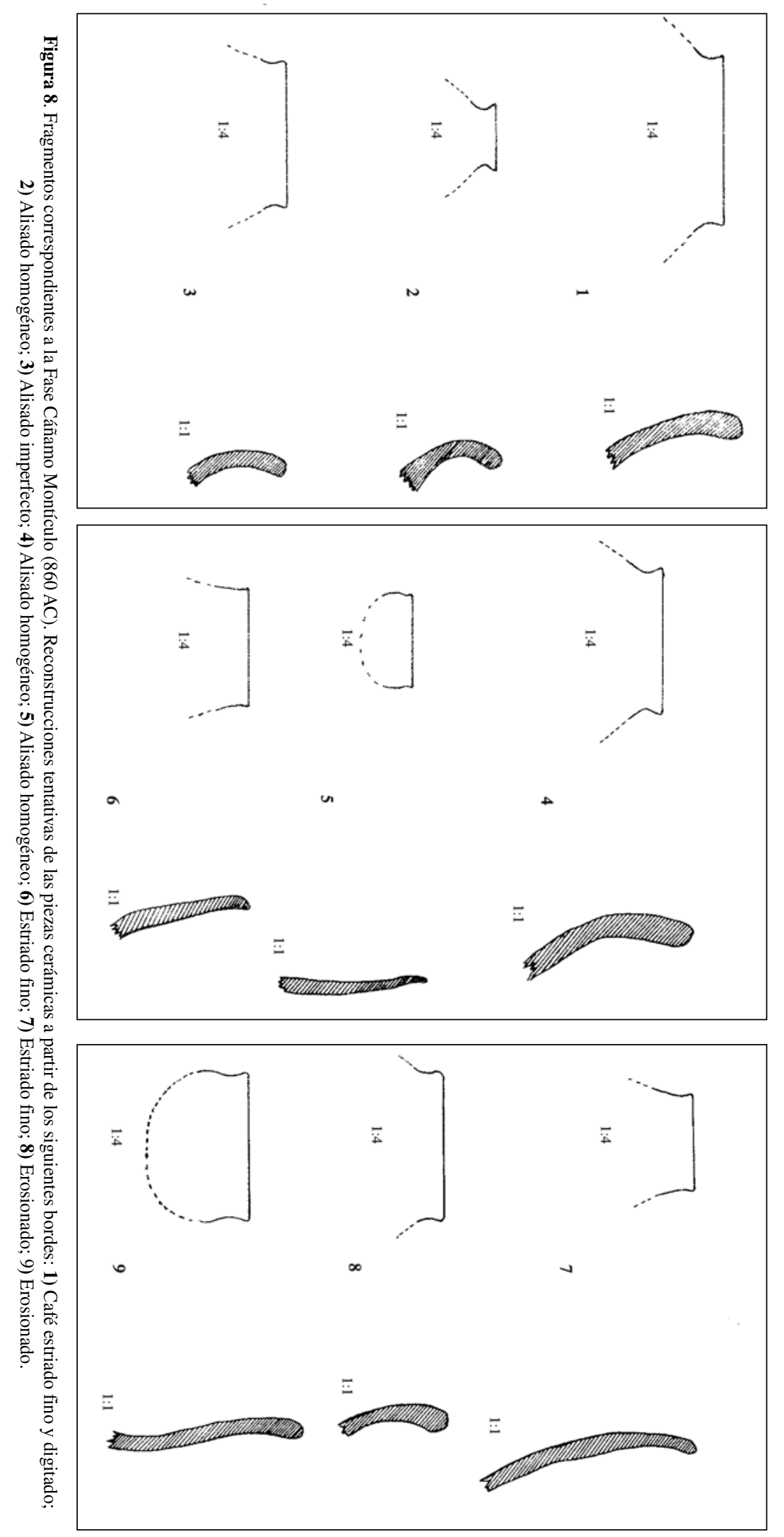

37 
efecto, algunas diferencias culturales deben explicarse por la naturaleza productiva y aun cronológica de la fase Alto Ramírez de Azapa. Sin embargo, el estímulo altiplánico sería válido tanto en Azapa como en Cáñamo para acondicionar el desarrollo temprano agrocerámico en poblaciones de tradición marítima.

En relación a la cerámica temprana del Noroeste Argentino, como la registrada en el sitio Las Cuevas -cerro El Dique- fechada en 535 AC (Raffino y Togó 1976), se presentan algunas similitudes en relación a las formas con bocas anchas, bases redondeadas y bordes engrosados, además del tratamiento alisado y semipulido, incluyendo superficies monócromas con manchones y cambios de tonalidad. Sin embargo, a juzgar por las muestras recibidas (gentileza de R. Raffino), podemos señalar que existen diferencias consistentes. En el caso de cerro El Dique existe un tratamiento de mejor pulimento, con formas muy particulares de vasos cilíndricos de base plana, ollas globulares con bocas restringidas, presencia de asa vertical y mamelones, incluyendo superficies grises pulidas, rojo pintado, rojo pulido y corrugado.

En relación a la cerámica Wankarani (Ponce 1970), se destacan ciertas similitudes con los tipos espatulados y pulidos, pero tomando en cuenta un fragmento pulido (gentileza de C. Ponce) podemos señalar que el nivel tecnológico del pulimento y aun el tratamiento de cocción es superior al conjunto de Cáñamo. Las fechas radiocarbónicas de Wankarani se inician muy tempranamente hacia $1210 \mathrm{AC}$, por lo que se podría presuponer que un estímulo de esta naturaleza pudo ser responsable de las derivaciones de esta cerámica temprana hacia la vertiente del Pacífico. Se puede establecer que durante la Fase Cáñamo Montículo (860 AC) se desarrollaba en los valles bajos una población de una tradición marítima que asimiló un proceso de cambios agrocerámicos derivados de diversos ejes establecidos en las tierras altas. Hemos observado relaciones estilísticas muy concretas entre la cultura Pucara y la fase Alto Ramírez del valle de Azapa. Del mismo modo, estamos estudiando similares relaciones entre Wankarani Medio (250350 AC) y un asentamiento del Loa Superior. Por consiguiente, las relaciones entre Wankarani Temprano y otros asentamientos marginales, como el caso de Cáñamo, podrían ser parte de un temprano proceso de expansión altiplánica que hasta ahora no se ha definido convenientemente. Estas consideraciones se apoyan también en los propios maíces de Cáñamo, que corresponden a una variedad tunicada (Cutler
1946) con rasgos similares a los híbridos entre Guaraní -Valle y Coroico- Valle. Su traslado hacia esta vertiente occidental parece comprometerse con la expansión antes referida.

\section{Vegetales modificados}

Se registra una variada industria de espinas de cactus, algunas utilizadas como alfileres, agujas, o pasadores, y otras más cortas, quizás usadas como barbas de arpón. Se suman algunos alfileres con tope y otros especímenes curvados con funciones de anzuelo (Figura 7, $\mathrm{n}^{\circ}$ 5), los cuales presentan alteraciones por quemazón, que estaría demostrando una técnica vinculada con las curvaturas de los ganchos. Esta industria, en general se presenta en todos los estratos, aunque habría una mayor proliferación especialmente de anzuelos en la etapa cerámica relacionada con una mayor actividad pesquera.

\section{Alimentos vegetales}

Se han registrado aproximadamente 40 mazorcas de maíz (Zea mays) completas y algo más de 30 fragmentadas, especialmente en el estrato I. El test cuantitativo realizado en 1977 verificó la presencia de 22 evidencias en el estrato I, lo cual, a juzgar por el volumen de la excavación, representa una densidad significativa. Esta variedad de maíz corresponde a tunicata (M. Muñoz, com. pers.), la cual se cultiva esporádicamente en Argentina, Bolivia, Paraguay y Perú.

El algodón (Gossypiun sp.) aparece en forma de vellones sueltos o con la semilla incluida. Al igual que en el caso del maíz, no cabe duda que fue cosechado fuera de Cáñamo, y trasladado desde hábitats agrarios primarios. El algodón está comprobado en el estrato I, en plena sincronía al momento del cambio agrocerámico y su uso perfeccionó la eficiencia de la pesca en la última etapa del yacimiento.

La presencia de algarrobo (Prosopis sp.), al igual que el maíz, es un excelente indicador de un proceso de equilibrio dietético que trata de establecerse en los estratos cerámicos (Fase Cáñamo Montículo). Los registros de semillas y vainas de algarrobo son cuantiosos en el estrato I y disminuyen gradualmente hacia el estrato IV. Esto indicaría que desde etapas tempranas los grupos de la Fase Cáñamo Precerámico exploraban la Pampa del Tamarugal, pudiendo entrar en contacto con comunidades que ya habían establecido un manejo adecuado de agricultura primaria en 
valles fértiles cercanos. De este modo, tanto el maíz (almidón) como el algarrobo (glucosa) implementaron la dieta en la etapa final del yacimiento.

Hay escasa presencia de calabaza (Cucurbita sp.) en el estrato superior, en asociación a la imposición del cambio agrario.

Finalmente, se han ubicado bulbos de la familia Tecofiláceas de pequeño volumen, envueltas en fibras de color café, ubicadas especialmente en los estratos cerámicos (Figura 7, no 7). Estos bulbos corresponden a cormos de la variedad Zephira elegans D. Don, que crecen en los lomajes de la cordillera de la Costa de Tarapacá a Atacama. Aunque no hay referencias sobre su consumo alimenticio, hay otros géneros similares, como Conanthera, que ha sido utilizada para estos fines (M. Muñoz, com. pers.). Es probable que estos bulbos hayan complementado la dieta marítima, especialmente en los estratos tardíos, cuando se planteó el proceso de equilibrio alimenticio.

\section{Misceláneos}

Se han contabilizado algunos protúberos de cuero de lobo, que constituyen remates terminales de bolsas de vejigas, utilizadas para contener líquidos. Son registros típicamente tardíos (estratos I y II).

Se agregan algunos fragmentos de mineral de cobre, también ubicados en los estratos cerámicos, que corresponden a óxidos de alta ley, seguramente relacionados con una industria metalúrgica incipiente. Sin embargo, no hemos registrado artefactos propiamente fundidos. Un fragmento de un posible artefacto de cobre resultó ser una pieza de cobre nativo machacado (Díaz et al. 1972).

El registro de una garra de ave terrestre perteneciente a la familia Falconidae podría ser un cernícalo, halcón peregrino, falco semoralis o, posiblemente, un peuquito Accipiter chilensis, aunque este último habita más al sur de esta región (P. Drouilly, com. pers.). Esta única evidencia demuestra el déficit de aves terrestres en la localidad.

Se han inventariado algunos coprolitos tanto humanos como animales del estrato I. Los coprolitos humanos poseen una gran cantidad de semillas y fibras de algarrobo, y en un caso, la observación macroscópica determinó la presencia de cartílagos de pescado, señalando una dieta mixta. El hecho de que estos coprolitos presenten restos de algarrobo predominantemente se debería a la glucosa contenida en este alimento, la cual no es atacada por los jugos gástricos. En oposición, tanto la carne de pescados como de moluscos es más fácilmente digerida, igualmente los cartílagos, ricos en calcio. Estas deposiciones confirman el interés por la recolección de algarrobo.

También se han registrado algunos coprolitos de camélidos en el estrato I, seguramente vinculados con caravanas de llamas mantenidas en torno a los desperdicios. Si aceptamos que la captura de guanaco se realizaba en diversos ámbitos de la cordillera de la Costa, resulta dudoso suponer que estos coprolitos pertenezcan a esta especie silvestre.

Los registros de fibras con nerviación paralela pertenecen a tallos de totora (Cyperus sp.) y juncos (Scirpus sp.), los cuales son útiles para la fabricación de cordelería, cesterías, esteras, etc. Como estas plantas crecen en zonas húmedas, creemos que fueron transportadas desde ambientes relativamente cercanos a Cáñamo.

\section{Fauna marítima}

De acuerdo a nuestro test cuantitativo de dieta (no publicado en esta oportunidad) podemos inferir que la alimentación básica de los grupos de Cáñamo estuvo orientada hacia la explotación del mar. En los niveles precerámicos, los mariscos más recolectados, en orden de prioridad, fueron los siguientes: erizo (Loxechnus albus), apretador (Amphineura sp.), lapas (Fisurellas sp.), locos (Concholepas sp.), conos (Turritela singulata), almejas (Protothaca thaca) y caracol negro (Tegula atra). En los niveles cerámicos estos rubros aumentaban consistentemente. Los grupos de mariscos menos económicos como choro azul (Choromytilus chorus), picoroco (Balanus sp.), porcelana (Oliva peruviana), chorito chico (Semimytilus algosus), ostión (Chlamis purpurata), entre otros, se presentan en ambas divisiones con muy baja frecuencia.

Llama la atención la notable abundancia de erizos en el estrato I, lo cual demostraría, al parecer, un énfasis en implementar el déficit de agua local (utilización del "agua" del erizo). Opuestamente, la escasa presencia de almejas y choro azul guardaría relación con el escaso desarrollo de playas arenosas. De este modo prevalece el marisco proveniente de un litoral rocoso, en donde el papel del apretador, 
lapas y locos es distintivo, explicando el uso de los chuzos y desconchadores.

Los restos de pescados aparecen desde los primeros estratos precerámicos, pero se intensifican gradualmente hacia los estratos cerámicos en estrecha relación con la proliferación de anzuelos y lienzas. Tomando en cuenta la cuantificación total, podemos resumir que esta población tenía hábitos más recolectores que pescadores.

En cuanto a las aves marinas, sabemos que se cazaban a través de todo el depósito, aunque sus registros son francamente dominantes en el estrato I, señalándose una clara preferencia en la captura del llamado pato guanay (Phalacrocorax bougainvilus).

La caza de mamíferos marinos es escasa a través de todo el yacimiento.

\section{Secuencia cultural y cronológica del distrito arqueológico}

Hemos revisado diversas fuentes relacionadas con colecciones procedentes del distrito de Cáñamo:

a) Seminario Medio conducido por Zlatar (Díaz el al. 1972), en donde se presenta un análisis taxonómico de la excavación realizada en el sitio Cáñamo 1 durante los años 1964-1965, conducida por el primer autor. En el cuadro adjunto aparece comprobada esta colección bajo el rótulo de Cáñamo 1 (1964).

b) Colección Ancker Nielsen (Museo Arqueológico de la Universidad de Chile, Iquique), quien excavó en 1936 un sector de enterramientos asociado a un basural conchífero ("Cáñamo norte"), el cual correspondería al sitio Cáñamo 2, según nuestra nomenclatura.

c) Colección procedente de nuestro test estratigráfico realizado en 1977.

En total, hemos contado con cuatro determinaciones radiocarbónicas para deslindar cinco fases correspondientes a diversos asentamientos humanos que fluctúan desde 2010 AC hasta aproximadamente 1000 DC. Por esta razón se señala que la delimitación de estas fases es tentativa.

Los datos obtenidos de las fuentes antes señaladas se muestran en la Tabla 2, la cual incluye 117 rasgos culturales presentes en uno o más sitios, separados en las diversas fases propuestas.

A continuación se realiza un examen crítico de los datos de la Tabla 2 para luego comentar la definición de las diversas fases de desarrollo:

1. Las colecciones correspondientes al sitio Cáñamo 1 (excavación de 1964) presentan una información bien documentada que hemos utilizado para definir la Fase Cáñamo Precerámico, integrando, a su vez, los datos del test de 1977. Esta fase presenta una datación inicial algo antes de 2010 AC (TK-102: 3960ะ136 AP; Núñez 1976).

2. La Fase II, llamada Cáñamo Montículo, reúne materiales registrados en los estratos I y II con fragmentos cerámicos predominantes, haciéndose esto más elocuente en el estrato I. Planteamos esto debido a que en Cáñamo 1 los últimos estratos precerámicos registran escasos fragmentos alfareros que se consideran dentro de una etapa transicional. Esta fase, al igual que la anterior, se compone de desperdicios marítimos y posee tres dataciones procedentes de una misma muestra: 1210 (considerada incorrecta según el laboratorio), 820 y 890 años AC (TK-103: 2840 y 2770 AP; Núñez 1976). De las dos últimas se obtuvo un promedio de $860 \pm 90 \mathrm{AC}$. Por esto, hemos situado el desarrollo central de la Fase II hacia $860 \mathrm{AC}$, ya que su tiempo determina la etapa nuclear del estrato I o Amarillo. El estrato II también se ha incluido dentro de esta fase a través de sus componentes cerámicos, aunque creemos que su datación podría ser algo más temprana que la fecha precedente. La nueva muestra radiocarbónica resultante de nuestro test de 1977, corresponde también a carbones entremezclados con desperdicios de alimentos localizados en un nivel nuclear del estrato I, sin ninguna posibilidad de perturbación, apoyando el tiempo conocido del pleno desarrollo del estrato I o Amarillo. La fecha recibida es de 870 AC (Gak-6883: 2820 100 AP). Esta datación afianza las dos anteriores consideradas coherentes, y confirma el promedio de $860 \mathrm{AC}$, que serviría para establecer un hito cronológico seguro para los componentes cerámicos agrarios tempranos que caracterizan a esta fase.

3. La Fase III se denomina Cáñamo Golfo y está representada en un cementerio (Cáñamo 12) en donde controlamos 12 enterramientos de los cuales algunos estaban visiblemente perturbados. No existen determinaciones radiocarbónicas, pero la presencia 


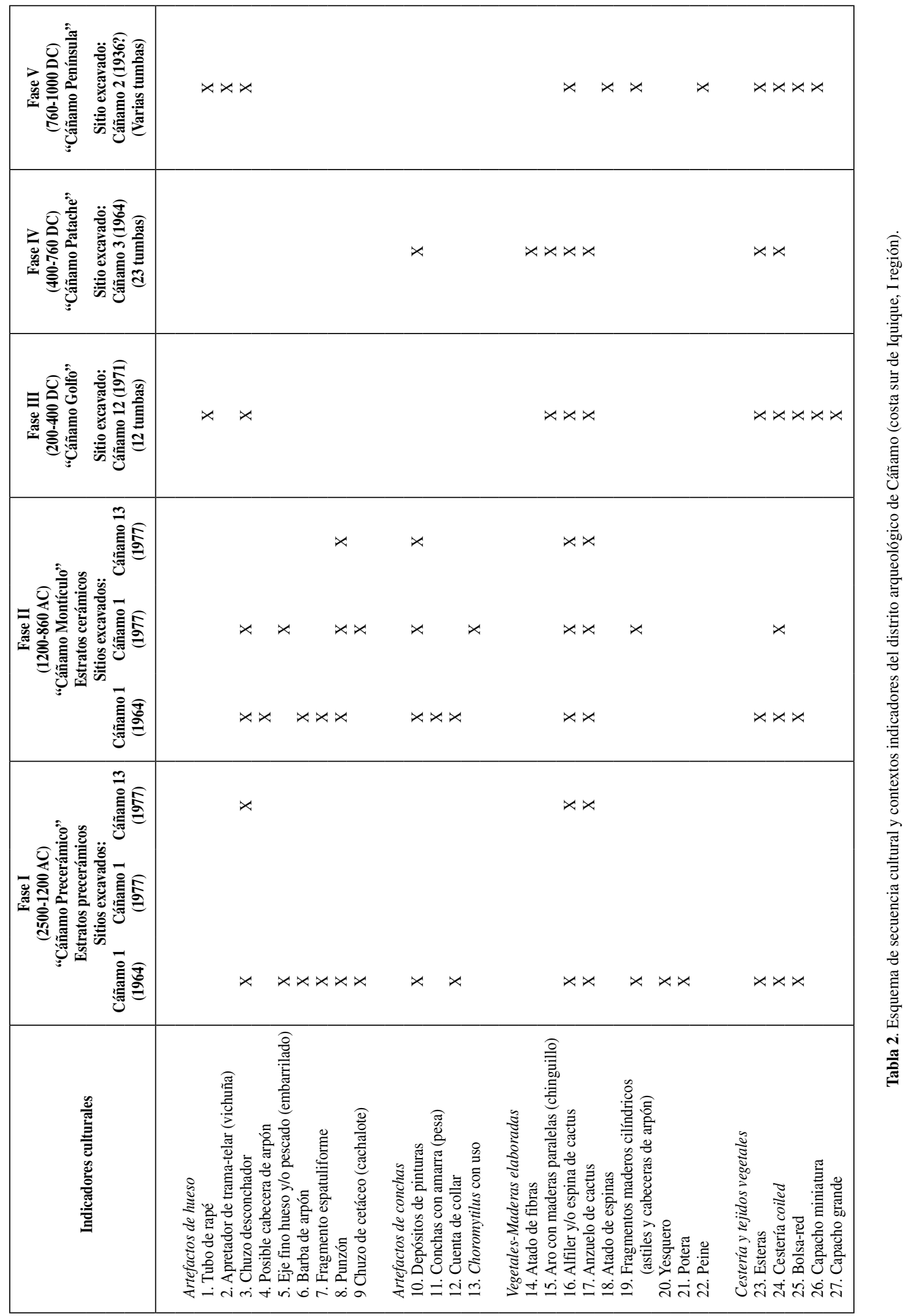


LAUTARO NUÑEZ A., CORA MORAGAS W.

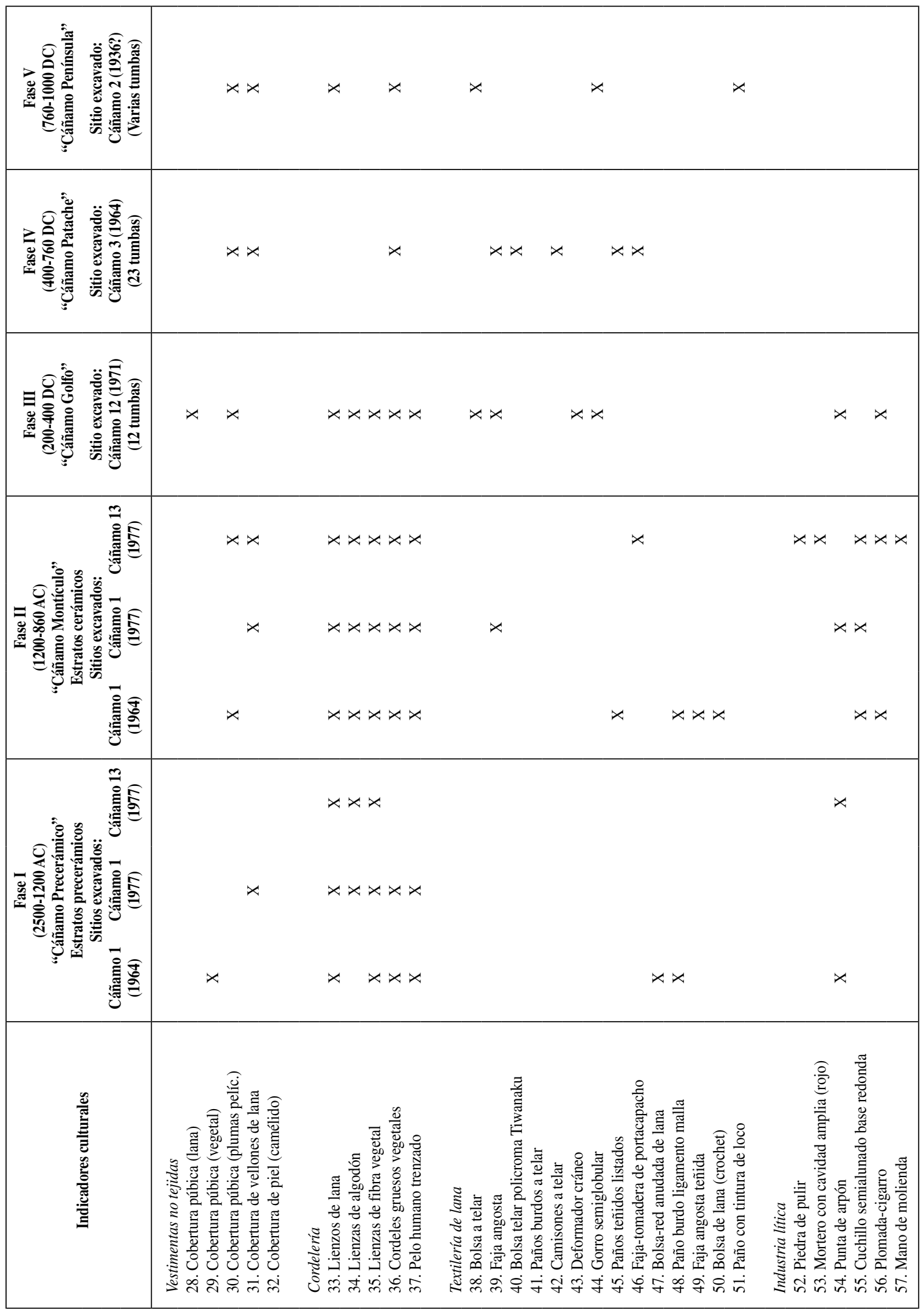




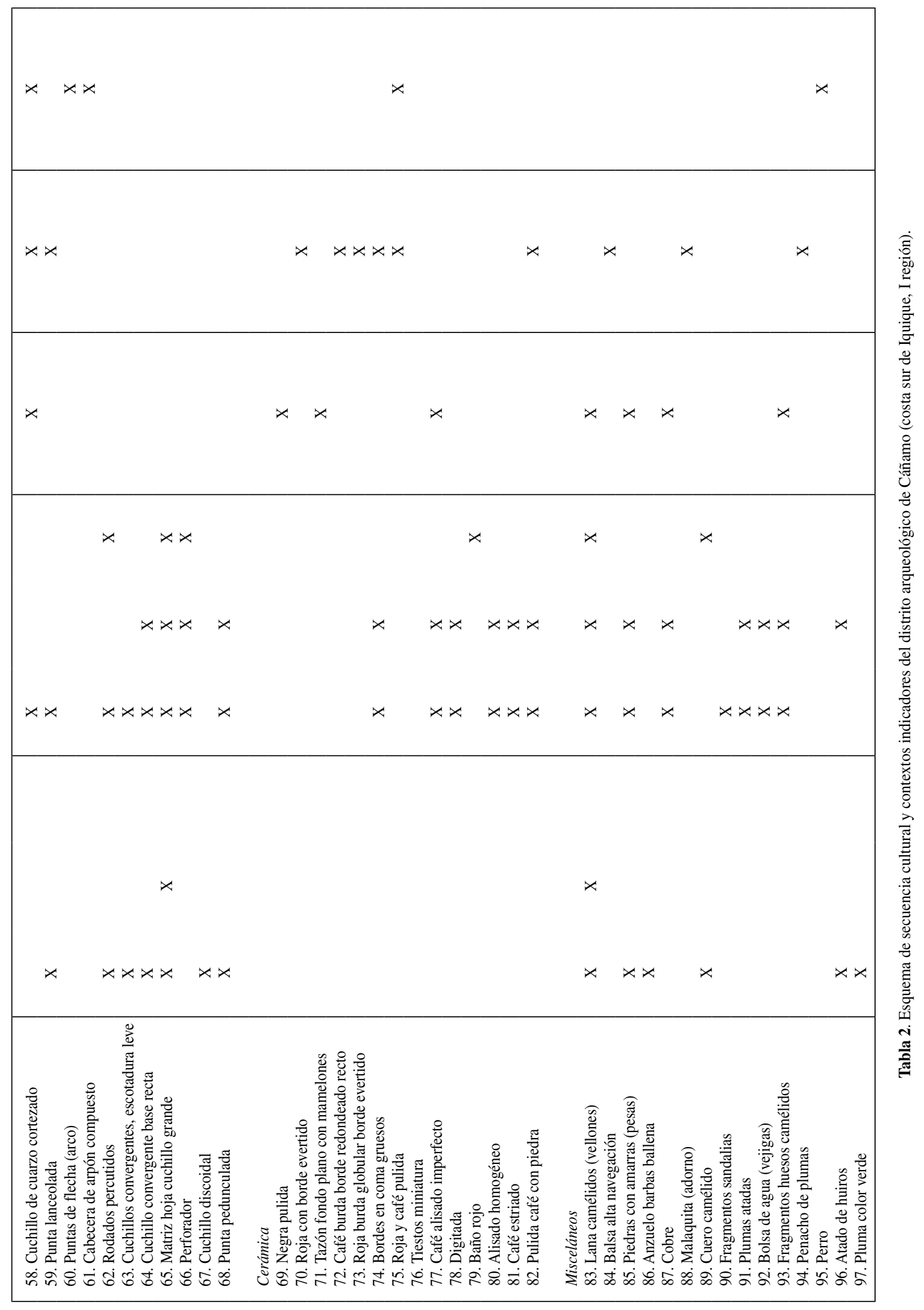


LAUTARO NUÑEZ A., CORA MORAGAS W.

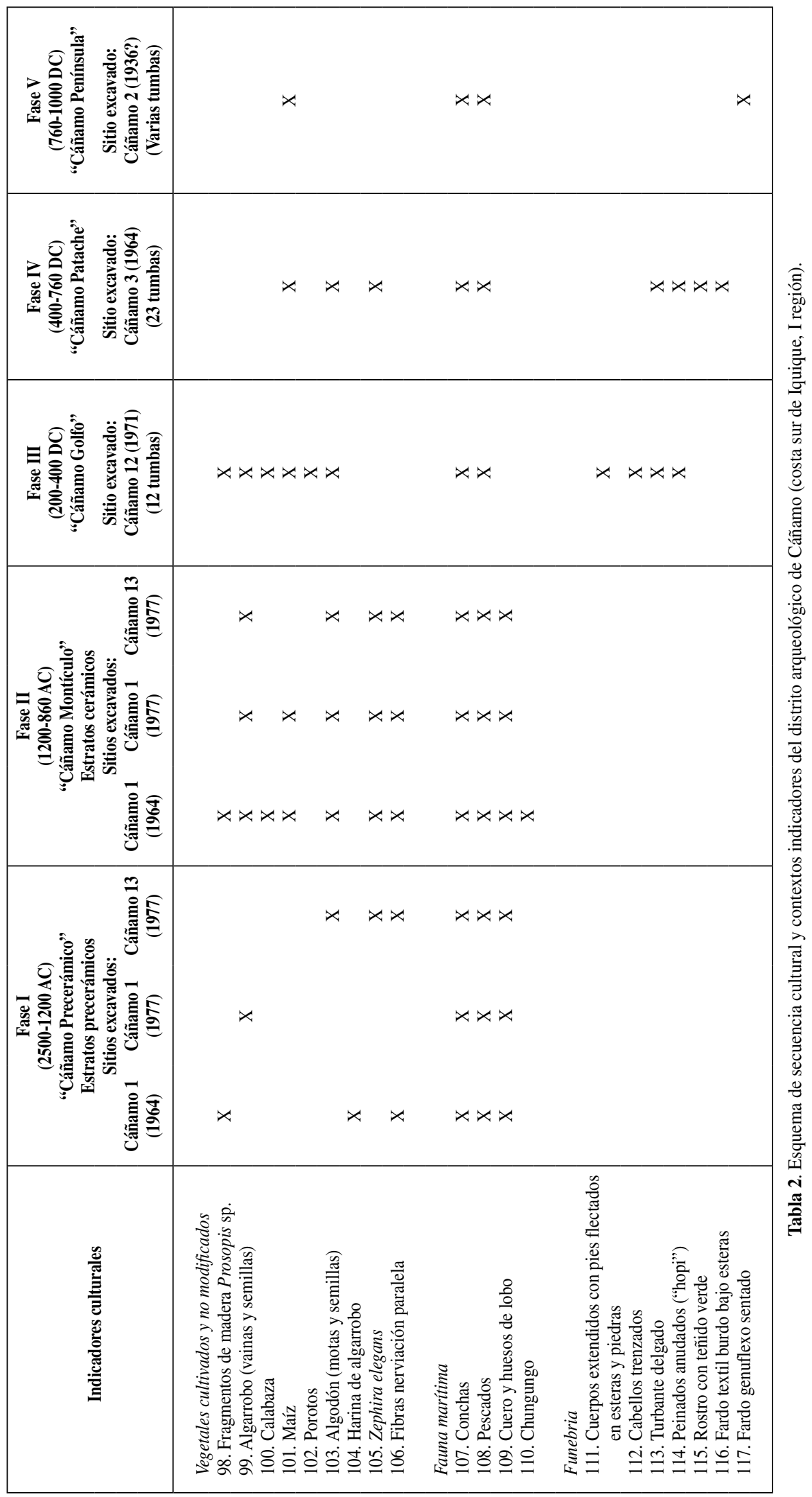


de cerámica negra pulida podría implicar alguna conexión con poblaciones tempranas similares a las registradas en la aldea de Caserones (Núñez 1976), o a derivaciones periféricas de la tradición negra pulida de los oasis de San Pedro de Atacama. Esta cerámica típica de San Pedro de Atacama ha recibido determinaciones radiocarbónicas fluctuantes entre 200-300 DC (Le Paige 1963), por lo tanto situamos esta fase dentro de este rango de tiempo, aunque sin poder confirmarlo plenamente.

4. La Fase IV ya se había denominado Cáñamo Patache (Núñez 1976) y se basa en los contextos funerarios de 23 tumbas con escasa perturbación, estudiada por uno de los autores en el sitio Cáñamo 3. Existe una datación radiocarbónica de 760 DC (TK-101: $1190 \pm 60$ AP). Esta fecha es coherente y se asocia al desarrollo de tiestos cerámicos vinculados con poblaciones interiores con engobe rojo, bases semiaplanadas y paredes verticales. Además hay un fragmento fino tejido a telar, asociado a equipos de alucinógenos, con una decoración del típico ojo Tiwanaku con su división simétrica y cambio de color. Tomando en cuenta estos antecedentes, se establece esta fase dentro de un rango fluctuante entre 400 a $760 \mathrm{DC}$, o algo posterior.

5. La Fase V o Cáñamo Península consiste en un sector de enterramientos que Nielsen denominó "Cáñamo norte" (Cáñamo 2). Se desconoce la cantidad de tumbas registradas y no hay determinaciones cronológicas absolutas. Sin embargo, las prácticas funerarias a base de fardos genuflexos sentados y los componentes culturales ausentes en las fases anteriores nos permiten suponer el establecimiento de una población tardía con rasgos culturales que recuerdan al Complejo Pica. Estas consideraciones sugieren una ubicación temporal variable entre 760 y 1000 DC, incluyendo una cercanía hacia el contacto europeo.

Un examen general de estas poblaciones advierte la ausencia de los típicos enterramientos Chinchorro, como a su vez no es muy densa la presencia de poblaciones tardías derivadas del Complejo Pica. Sin embargo, ambas poblaciones están bien representadas en los yacimientos de caleta Patillos, ubicada inmediatamente al norte de Cáñamo, con lo cual se complementa globalmente la secuencia. No obstante, tanto en Patillos como en Cáñamo no se han registrado hasta ahora grupos de enturbantados o portadores de agricultura primaria semejantes a los ubicados en Arica, Pisagua y Tarapacá, debido seguramente a la ausencia de recursos de agua exigidos en este estadio crítico de desarrollo.

Con estos antecedentes podemos separar las fases de acuerdo al comportamiento de la cultura material en términos de continuidad y cambio:

Rasgos continuos. En esta categoría incluimos los indicadores culturales que persisten tradicionalmente en casi la mayoría de las fases: $3,10,16,17,19,23$, $24,25,29,33,35,36,37,83,85,98,99,103,105$, 106, 107, 108, 109 (Tabla 2). Estos 23 rasgos están presentes tanto en las fases precerámicas como cerámicas de los basurales, y aun en la mayoría de los cementerios más tardíos. Indican una extraordinaria conservación de industrias y hábitos que persisten dentro del distrito hasta tiempos muy tardíos, debido a la continuidad y conservación de los modos de explotación del litoral.

Al comparar los rasgos continuos o conservadores entre las fases I y II, además de los 23 rasgos comprobados anteriormente, válidos para la mayoría de los sitios, se suman ahora los siguientes: 5, 6, 7, 8, 9, $12,48,55,62,63,64,65,68,89$ y 96 . Estos factores estrechan aún más las relaciones de continuidad entre ambas fases.

Al comparar las fases Cáñamo Golfo y Cáñamo Patache, respectivamente, se observan rasgos continuos y variables. Los siguientes rasgos se presentan exclusivamente en la Fase Cáñamo Golfo: 1, 25, 27, $28,34,37,38,54,56,69,71,77,83,85,87,93,98$, $99,100,102,111,112$. Estos rasgos exclusivos suman un total de 22, pero a su vez se registran solamente en Cáñamo Patache los siguientes: 10, 14, 29, 40, $46,59,70,72,73,74,75,82,84,88,94,105,116$, 115. Si estos 18 rasgos se suman a los 23 exclusivos para Cáñamo Golfo se obtiene un total de 40 rasgos diferentes entre ambas fases.

Las relaciones entre ambas fases serían las siguientes: $15,16,17,23,24,30,36,39,41,43,45,58,101$, $103,107,108,113,114$. Estos rasgos funerarios suman en total 17 , los cuales son minoritarios en relación a las diferencias anteriores. Si se acepta que los rasgos diferenciados entre Cáñamo Golfo y Cáñamo Patache son tan diagnósticos como los componentes cerámicos, cultígenos y otros, podríamos asegurar una distancia temporal. Por otro lado, la persistencia en ambas fases de instrumentos de uso marítimo como el "chinguillo" de madera, presupone cierta continuidad en determinados instrumentos de 
trabajo marítimo, ya que esta distancia temporal parece ser relativamente estrecha. En consecuencia, ambas fases tienden a separarse incluyendo una leve proximidad entre ellas.

Las relaciones entre estas fases con Cáñamo Montículo, esta vez fundamentadas en desperdicios, señalan la presencia bilateral de rasgos continuos, como son los chuzos o desconchadores de hueso, depósitos de conchas para pintura, industria de quisco, esteras, cestería, entre otras, los cuales serían aportes desde la etapa precerámica a la siguiente agroalfarera. Sin embargo, las fases Cáñamo Golfo y Cáñamo Patache presentan componentes que definitivamente están ausentes en la Fase Cáñamo Montículo, dado a su incorporación posterior: 1, 15, 27, 28, 38, 41, 43, 54, 69, 70, 71, 72, 73, 84, 88, 94, 102.

La Fase V llamada Cáñamo Península no tiene datación radiocarbónica, y, al igual que las anteriores, sigue ofreciendo rasgos culturales continuos, que provienen de los depósitos precerámicos: desconchadores de hueso, industria de cactus, astiles y cabeceras de arpones, esteras, cestería, coberturas púbicas de fibra vegetal y de plumas de pelícano, cuchillos de cuarzo cortezado, etc. A pesar de esto, aparecen componentes típicos ausentes en las fases anteriores: 2, 22, 26, 42, 44, 51, 60, 76, 117.

Al revisar la Tabla 2, podemos deducir un proceso de adaptación al ambiente marítimo representado a través de poblaciones Chinchorro que debieron explotar el área entre 3050 y 2140 AC (Núñez 1976). Hasta ahora no se han ubicado poblaciones preChinchorro relacionadas con los contextos asociados a anzuelos de concha. De ser esta una ausencia segura tendríamos que presuponer que las poblaciones de esta naturaleza no ocuparon ambientes desérticos carentes de recursos de agua consistentes. De este modo, las tradiciones "chinchorroides", como las registradas en la desembocadura del río Loa, datadas en 2830 AC (Núñez et al. 1974), pudieron dar lugar hacia $2010 \mathrm{AC}$ a los primeros componentes precerámicos de Cáñamo. De uno u otro modo, la población precerámica inicial agrupada en la Fase I fue esencialmente marítima y se estableció a través de varios campamentos en el sector de la paleopenínsula. La relación entre fogones y desperdicios (Cáñamo 1) demuestra que las viviendas se establecieron en el mismo lugar. La supervivencia de estos rasgos continúa hasta la incorporación de los componentes cerámicos tardíos.
La Fase II, Cáñamo Montículo, continúa con las tradiciones marítimas anteriores, pero incorpora nuevos elementos culturales (cerámica) y alimenticios (cultígenos), enfatizando más aún la recolección vegetal (algarrobo). Estos cambios debieron ocurrir algo antes de $860 \mathrm{AC}$, dentro de una población local experta en el manejo de los recursos marítimos. Los cambios señalados se harían presentes a través del desplazamiento de un grupo que estaba en contacto directo con explotaciones agrarias primarias en posesión de nuevas técnicas de manufacturas complejas (cerámica), incluyendo, probablemente, el control de crianza y posibles caravanas de llamas, inferido a través de algunos coprolitos de camélidos ubicados en Cáñamo 1. Estos nuevos aportes foráneos se intercalaron en un grupo que explota el litoral, otorgando otros alimentos tendientes a un equilibrio dietético. Podría también suponerse que los cambios comprobados habrían derivado de incursiones hacia tierras interiores, de parte de algunos grupos marítimos locales. De acuerdo a nuestra información, ambas alternativas deberán ser sometidas a mayores pruebas. Los agentes de cambios agrupados en la Fase II continúan estableciendo los campamentos en torno a los montículos bajos de desperdicios, en el sector de la paleopenínsula, compartiendo una matriz tecnocultural local.

La Fase III, Cáñamo Golfo, presenta algunos cambios consistentes en sus prácticas de enterramientos (Cáñamo 12), ya que sitúa su lugar de funebria fuera del sector de la paleopenínsula, esta vez en el borde del sector del paleogolfo. Representa una organización social más compleja con un tratamiento funerario complicado, independiente del área que tradicionalmente se establecía para estos fines. Sin embargo, su hábitat se habría ubicado también en el sector de la paleopenínsula. Se orientaban principalmente a la explotación marítima pero son portadores de rasgos muy particulares: porotos, cerámica negra pulida, capachos, etc., que hacen pensar en una relación directa con asentamientos en valles y oasis cercanos similares a los registrados en la quebrada de Tarapacá, en Tarapacá 40B y en la aldea de Caserones (Núñez 1976). Esta fase parece representar una colonización independiente del desarrollo marítimo local, derivándose de desplazamientos de grupos con un nuevo manejo agrocerámico más avanzado que por razones de complementación de dietas y aun hasta por presión demográfica, tienden a interferir el desarrollo de las poblaciones esencialmente marítimas. 
Durante la Fase IV Cáñamo Patache, estas influencias de hábitats interiores se ponen aún más de manifiesto. Aunque la población sigue siendo principalmente marítima, se observa una creciente complejidad en la organización social, a través de nuevos hábitos funerarios en el lugar más distante de los sectores de paleopenínsula y golfo, respectivamente, en donde se habían establecido en las fases anteriores. Esta complejidad se advierte en la preparación de una cerámica técnicamente bien lograda con engobe, bases planas y mamelones, asociados a equipos de insuflación de alucinógenos, tejidos policromos a telar, que incluye un motivo Tiwanaku. A pesar de estos componentes exógenos, llama la atención que el grupo ha preparado técnicas de exploración y explotación marítima hasta ahora nunca conocidas en el área, como es el caso de una balsa de alta navegación con proa y estabilizadores. Estas innovaciones trascendentales podrían suponerse que son parte de los nuevos rasgos interiores que se van nucleando dentro de la población local esencialmente marítima. Continúan utilizando la vieja industria de anzuelo de quisco, con lo cual se demuestra la coexistencia con comunidades precedentes.

Al margen de sus hábitos funerarios (Cáñamo 3) no conocemos campamentos directamente relacionados con esta fase. Sin embargo, es probable que en el área de la paleopenínsula más de algún montículo no excavado pueda corresponder a la Fase Cáñamo Patache. Sus rasgos físicos (J. Munizaga, com. pers.) pertenecen a un tipo físico mongoloide con aparato masticatorio desarrollado; presentan fosas nasales anchas y órbitas de mediana altura, rasgos que son relativamente frecuentes en el litoral del norte de Chile. Enfatizan la deformación craneana intencional, que varía entre el tipo tabular oblicuo y el anular oblicuo, con algunos casos de pseudocircular. La aparición del pseudocircular se debería al empleo de técnicas combinadas entre las dos anteriores: por esto se puede postular que dentro de esta población se establecía gradualmente un cambio en el tipo de deformación que sigue la siguiente gradiente: anular-pseudocircular-tabular oblicua.

Esta población presenta evidencias de por lo menos tres generaciones simultáneas en el lugar, con una alta mortalidad infantil, que ocurre dentro de una organización de familia extensa. Este grupo, hacia 760 DC, no había logrado aún un régimen de adaptación adecuado a la explotación marítima, tal vez por el aporte de grupos con deformación tabular-oblicua provenientes de tierras interiores y que consecuentemente se desajustaron en el medio marítimo. Sea como fuere, el estado de la salud de algunos individuos es muy precario (presencia de fracturas y otras patologías óseas). Los desgastes dentarios confirman la evidencia arqueológica, puesto que su alimentación proviene del mar y de alimentos agrarios. De esto deducimos que debieron abandonar temporal o definitivamente hábitats agrarios interiores y perdurar en la costa por un corto tiempo relativo, aunque no podemos establecer relaciones de retorno o situaciones de disolución entre las comunidades costeras. El proceso de deformación transicional recuerda evidencias similares registradas en el cementerio Tarapacá 40A y B en la quebrada de Tarapacá, en donde una población de enturbantados fechados entre 290-360 DC transita gradualmente hacia una etapa con contactos Tiwanaku, con proliferación de agricultura temprana y desarrollo de la deformación tabular oblicua, reflejando aportes étnicos foráneos que pudieron alcanzar la costa desértica más tardíamente.

La Fase V, Cáñamo Península, representa al momento más tardío de ocupación a través de varios basurales dentro del área de la península. Las evidencias utilizadas provienen del sitio Cáñamo 2, caracterizado por fardos funerarios en oquedades dispuestas en el basural. Los cuerpos se encuentran en posición genuflexa, envueltos en camisones tejidos a telar. Son similares a los paquetes funerarios del Complejo Pica y equivalentes registrados en la quebrada de Tarapacá. Por esta razón, esta fase parece ubicarse desde 1000 DC hasta tiempos de contacto europeo. Algunos rasgos típicos de esta fase son la cerámica miniatura, presencia de perros, capachos en miniatura, sombreros y otros rasgos interiores. En esta fase no parece haber mezcla con poblaciones locales, sino más bien se trataría de una colonización tardía procedente de valles y oasis interiores establecidos bajo un patrón vertical en vías de explotación de excedentes marítimos y de fertilizantes dentro del sistema de caravanas impuesto por el tráfico interregional tardío (Núñez 1977)

\section{Conclusiones preliminares}

Los análisis cuantitativos de dieta demuestran una adecuada adaptación al ambiente marítimo desértico, especialmente durante las dos primeras fases. Se observa cierta continuidad cultural a base del desarrollo de una economía conservadora 
enfatizándose una recolección inicial intensiva. En las fases cerámicas posteriores, hay una mayor dedicación a la actividad pesquera, manteniéndose el alto índice de recolección y un déficit notable de caza. Al margen de esta explotación destaca un manejo dinámico del espacio a través de recolección de algarrobo y otros vegetales procedentes de áreas distantes. También se advierte en la fase cerámica temprana una clara orientación a lograr un equilibrio de dietas con cultivos agrarios procedentes de otros hábitats también distantes. Estos, al parecer, suplementan la alimentación a través de una presión demográfica creciente, opuesta a las poblaciones iniciales caracterizadas por su baja densidad. Este suplemento se fundamenta en contactos y conexiones con poblaciones agrarias establecidas en valles bajos desde $1000 \mathrm{AC}$ en adelante. De estos centros proceden cultígenos y tecnologías que no producen cambios cualitativos en el patrón habitacional ni en el desarrollo cultural específico. Esta continuidad de las tradiciones marítimas persiste en la mayoría de las fases, pero a su vez a partir de la Fase Cáñamo Montículo el litoral queda expuesto a constantes colonizaciones procedentes de tierras fértiles. En términos generales, el litoral de Cáñamo presenta cuantiosos recursos alimenticios, capaces de sostener a densas poblaciones; sin embargo, la limitación hídrica constituyó un freno crítico.

El proceso de cambios agrocerámicos actuó sobre una población con componentes Chinchorro y derivados. Estos componentes se ubican dentro de un estadio de desarrollo similar a los registrados en Quiani 7 (Dauelsberg 1974) y Camarones 15 (Rivera 1976) datados en 1640 y 1110 AC, respectivamente. Sin embargo, los contextos de los yacimientos señalados presentan una alta complejidad funeraria como resultado de un desarrollo más eficiente, puesto que el ambiente de estos dos últimos valles (Azapa y Camarones) ofrece recursos óptimos para una subsistencia equilibrada. Los contactos agrocerámicos ocurridos en Cáñamo hacia 860 AC, y aun algo antes, debieron reflejarse en el litoral de los valles más septentrionales, a través de los primeros estímulos presionados por poblaciones foráneas provenientes de tierras altas. Sin embargo, estos componentes tempranos de Cáñamo hasta ahora no se han registrado en otras localidades costeras del norte de Chile. Esta ausencia se debería, a nuestro juicio, a una falta de información.
Nuevas oleadas de poblaciones procedentes desde las tierras altas (subárea circumtiticaca) habrían causado un particular proceso de agriculturación en los sectores fértiles del litoral, a través de su funebria establecida en los valles de Arica, en Playa Miller 7 (Fase El Laucho, 530 AC), Azapa 70 (Fase Alto Ramírez, 490 AC), Azapa 84 (Fase Alto Ramírez, 410 AC). Estos demuestran una estabilidad ocupacional adecuada para iniciar un desarrollo agrario temprano. Una situación similar se presenta en las zonas fértiles de la desembocadura del Loa, con fechas que fluctúan entre 450 y 370 AC (Núñez 1971), incluyendo además los túmulos de Camarones con una datación de 320 AC (Schiappacasse y Niemeyer 1969).

Estamos en presencia de una población enterrada en túmulos que abarca varios valles bajos del norte de Chile, pero que no ocupa la costa desértica de interfluvio como es el caso de Cáñamo. La distancia temporal entre Cáñamo y la fecha más temprana de los túmulos de Arica es de 370 años, lo cual explica que los estímulos agrocerámicos de Cáñamo corresponden a una primera oleada foránea que merece una investigación más a fondo. La distancia entre Cáñamo y la Fase El Laucho, en donde también se manifiesta el contacto entre una población marítima local con rasgos nuevos agrocerámicos incipientes, es de 330 años. Esto confirma que el evento de Cáñamo es más temprano, y parece corresponder a uno de los primeros contactos con grupos que portaban soluciones agrarias y manufacturas complejas, en nuevos espacios fértiles occidentales, que debieron incluir controles tanto en el litoral fértil como en el desértico. Recientemente se conoce un caso de temprana colonización en la quebrada de Tarapacá, con cerámica cruda datada en 920 AC. $^{3}$

El foco de esta expansión agraria temprana se relacionaría con diversos ejes formativos que se alternaron en la Subárea Circumtiticaca (Pucara, Chiripa, Tiwanaku preclásico y las derivaciones más meridionales registradas en Wankarani). Estos estímulos habrían promovido un proceso de aculturación en respuesta a nuevos modos de explotación en donde el papel de la agricultura temprana sirvió de base formativa para el desarrollo cultural posterior en los valles fértiles. Sin embargo, en el caso de Cáñamo, estos estímulos se habrían diluido a raíz del carácter

\footnotetext{
3 D. True, 1973: Archaeological researches of the quebrada Tarapaca, $38^{\text {th }}$ Annual Meeting, Society for American Archaeology, San Francisco.
} 
desértico de dicho litoral. Estos primeros arribos en Cáñamo, establecidos en 860 AC, habrían abierto el litoral a atractivos contactos con hábitats agrarios, produciéndose una interacción cultural (equilibrio de dietas, traslados de cobre, conchas y otros rubros complementarios al altiplano).

Las próximas fases agrocerámicas (fases Cáñamo Golfo, Cáñamo Patache y Cáñamo Península) habrían arribado desde cabeceras agrarias interiores con una orientación colonizadora, al parecer dependientes de centros sociopolíticos más complejos. Como consecuencia se habrían establecido cambios culturales que alteraron la matriz marítima local. No se conoce con certeza cuál es el real sentido de las colonizaciones de las fases Cáñamo Golfo y Cáñamo Patache, respectivamente, pero sí está claro que cuando se desarrolla la Fase Cáñamo Península, el carácter colonial responde más bien a un patrón vertical, con dependencia directa de los oasis interiores (Complejo Pica Tardío).

La ausencia de componentes incas parece demostrar que los ambientes desérticos costeros están fuera del área de control, por tratarse de un sector con recursos naturales al margen de los intereses incaicos.

Nuestros reconocimientos en la costa desértica comprendida entre Pisagua y el Loa nos permitieron señalar al distrito de Cáñamo como un sector útil para establecer una secuencia a raíz de la variabilidad de sitios representados. En el resto del litoral se registran diversas fases aisladas que en conjunto apoyan la secuencia establecida. La Fase Cáñamo Precerámico, correspondiente a una etapa tardía, se manifiesta en diversos sitios con componentes asociados al anzuelo de cactus. Suponemos que algún montículo no excavado en Cáñamo podría representar una etapa anterior con mezclas de anzuelos de concha y cactus registrada por Sanhueza (com. pers.) al norte de Cáñamo (Fase Caramucho). En plena vinculación con sitios precerámicos se sitúan algunos cementerios Chinchorro Tardío (Patillos, Bajo Molle), población que hemos inferido en Cáñamo Precerámico. La Fase Cáñamo Montículo, portadora de la cerámica temprana, no tiene por ahora una distribución mayor. Hemos sugerido que la población con turbantes relacionada con los enterramientos en túmulos o con contacto con influencias Tiwanaku no se presenta en este litoral desértico. Salvo unos registros aislados ubicados por Nielsen en Punta Gruesa, se ratifica la ausencia antes señalada. La Fase Cáñamo Golfo presenta también una escasa distribución en el litoral, y algo similar ocurre con la Fase Cáñamo Patache. Por esto deducimos que tales colonizaciones abarcaron determinados enclaves del litoral. La Fase Cáñamo Península la hemos relacionado con una colonización tardía del Complejo Pica. Sin embargo, los principales factos funerarios relacionados con este Complejo los hemos observado en los sitios Bajo Molle, Los Verdes y Patillos. Finalmente, creemos que las mejores evidencias del complejo inca altiplánico corresponden a las registradas recientemente en Iquique por personal del Museo Regional de Iquique.

En el litoral desértico comprendido entre la desembocadura del Loa y Taltal se presentan yacimientos precerámicos en contacto con ocupaciones cerámicas (p.e., Punta Blanca). Los contextos de este sitio reflejan también un cambio agrocerámico que estaría relacionado con la introducción de poblaciones procedentes de los oasis de la Puna de Atacama (Núñez 1976). Estos habrían distribuido los componentes cerámicos pulidos tempranos en la costa, aproximadamente entre 200 a 300 DC o algo más tarde. Estos contactos pudieron ser aún anteriores si aceptamos que el comienzo de la utilización de la cerámica en estos oasis es previo al desarrollo de la cerámica San Pedro Negro Pulido. A partir de estos eventos se suceden otras colonizaciones con cerámica procedentes de estos oasis, que se establecen en secuencia con posterioridad a la cerámica negra pulida. De esta manera, se sugiere que la naturaleza de los cambios agrocerámicos tempranos en el litoral al sur del Loa guarda estrecha relación con una temprana expansión de las comunidades agroganaderas establecidas tanto en el Loa Superior como en los oasis de la Puna de Atacama. Estas colonizaciones habrían actuado como estímulos para establecer nuevos valores de interacción cultural, diferentes a la situación que hemos planteado en la costa al norte del río Loa. 


\section{REFERENCIAS CITADAS}

CERVELLINO, M. y F. TELLEZ, 1975-76. Emergencia y desarrollo en una aldea prehispánica en Quillagua, Antofagasta. Memoria de Título, sección Arqueología, Depto. de Ciencias Sociales, Universidad del Norte, Antofagasta.

CUTLER, H. C., 1946. Races of maize in South America. Botanical Museum Leaflets 12 (8): 257-275.

DAUELSBERG, P., 1974. Excavaciones arqueológicas en Quiani (provincia de Tarapacá, depto. de Arica). Chungara 4: 7-38.

DIAZ, M. R., C. MORAGAS, M. V. PEREZ, M. C. RODRIGUEZ, y M. VASQUEZ, 1972 Ms. Métodos de clasificación de materiales arqueológicos: Sitio Cáñamo. Seminario Medio, Depto. de Historia y Geografía, Universidad del Norte, Antofagasta (conducción de V. Zlatar).

FOCACCI, G., 1969. Un cementerio preagrícola en playa El Laucho (Arica, Chile). Rehue 2: 49-62.

LE PAIGE, G., 1963. Continuidad y discontinuidad de la cultura atacameña. Anales de la Universidad del Norte 2: 7-25.

MARINCOVICH, L., 1963. Intertidal mollusks of Iquique, Chile. Science Bulletin 16.

MORAGAS, C., 1977 Ms. Continuidad y cambio socioeconómico en una ocupación del litoral desértico. Distrito arqueológico de Cáñamo (norte de Chile), I región. Tesis de Título. Depto. de Ciencias Sociales, Universidad del Norte, Antofagasta.

NUÑEZ, L., 1971. Secuencia y cambio en los asentamientos humanos de la desembocadura del río Loa, norte de Chile. Boletín de la Universidad de Chile 112: 3-25.
_ 1976. Registro regional de fechas radiocarbónicas del norte de Chile. Estudios Atacameños 4: 74-123.

NUÑEZ, L., V. ZLATAR y P. NUÑEZ, 1975. Caleta Huelén 42: Una aldea temprana en el norte de Chile (nota preliminar), Universidad de Panamá, Ciudad de Panamá.

NUÑEZ, L. y J. VARELA, 1967-68. Sobre los recursos de agua y poblamiento prehispánico de la costa del Norte Grande de Chile. Estudios Arqueológicos 3-4: 7-41.

PONCE, C., 1970. Wankarani y Chiripa y su relación con Tiwanaku. Publicación de la Academia Nacional de Ciencias de Bolivia 25.

RAFFINO, R. y J. TOGO, 1975. El yacimiento arqueológico cerro El Dique (quebrada del Toro, prov. de Salta). Nota preliminar. Actas y trabajos del $1^{\text {er }}$ Congreso de Arqueología Argentina. Museo Histórico Provincial "Dr. Julio Marc", pp. 113-124, Rosario.

RIVERA, M., 1976. Nuevos aportes sobre el desarrollo cultural altiplánico en los valles bajos del extremo norte de Chile, durante el Período Intermedio Temprano. En Homenaje al Dr. Gustavo Le Paige, s. j., J. M. Casassas (Ed.), pp. 71-82. Universidad del Norte, Antofagasta.

SCHIAPPACASSE, V. y H. NIEMEYER, 1969. Comentario a tres fechas radiocarbónicas de sitios arqueológicos de Conanoxa (valle de Camarones, prov. de Tarapacá). Noticiero Mensual del Museo Nacional de Historia Natural 151. 